\title{
Arctic sea ice surviving the summer melt: interannual variability and decreasing trend
}

\author{
H. Jay ZWALLY, Per GLOERSEN \\ Cryospheric Sciences Branch, Code 614.1, NASA Goddard Space Flight Center, Greenbelt, Maryland 20771, USA \\ E-mail: jay.zwally@nasa.gov
}

\begin{abstract}
Sea ice surviving the summer melt season to become multi-year ice in the Arctic Ocean is of interest because multi-year ice significantly affects the ice-thickness distribution and the dynamics and thermodynamics of the ice pack in subsequent seasons. However, the amount of ice surviving summer melting has not been well determined because the time of the minimum ice area varies from region to region. A concept of local temporal minimum (LTM) accounts for non-simultaneity of the melt-freeze transition by determining the minima ice concentrations $\left(C_{\mathrm{LTM}}\right)$ on local spatial scales. $C_{\mathrm{LTM}}$ are calculated for $25 \mathrm{~km}$ gridcells using 24 years (1979-2002) of satellite passive-microwave data. The total area of ice surviving the summer melt $\left(A_{\mathrm{LTM}}\right)$ is given by spatial integration of $C_{\mathrm{LTM}}$. Over 24 years, the average $A_{L T M}$ is $2.6 \times 10^{6} \mathrm{~km}^{2}$ (excluding $\sim 0.7 \times 10^{5} \mathrm{~km}^{2}$ above $84^{\circ} \mathrm{N}$ ). In contrast, the average area $\left(3.8 \times 10^{6} \mathrm{~km}^{2}\right)$ of all ice types $\left(A_{S M}\right)$, measured when the total (simultaneous) ice cover is a minimum in daily maps in mid-September, is an often-used estimate of ice surviving the summer melting that is $\sim 45 \%$ too large. Over 24 years, the $A_{\text {LTM }}$ decreased by $9.5 \pm 2.2 \%(10 \text { a })^{-1}$ $\left(0.27 \pm 0.06 \times 10^{6} \mathrm{~km}^{2}(10 \mathrm{a})^{-1}\right)$, which is similar to the rate of decline of $A_{S M}$ and about three times the rate of the annual average. The time-of-occurrence of the LTM averaged over the perennial ice pack increased by 8 days from around 11 to 19 August, indicating a later ending of the melt season by about 3 days $(10 a)^{-1}$ as the summer pack declines. Estimates of multi-year ice in midwinter from passive microwave observations are $\sim 17 \%$ smaller than $A_{\mathrm{LTM}}$, suggesting that the microwave algorithm does not measure all the multi-year ice.
\end{abstract}

\section{INTRODUCTION}

The mass of the perennial ice pack in the Arctic Ocean is determined mainly by the annual melt/growth cycle and the export of ice through the Fram Strait to the East Greenland Sea. Multi-year sea ice, which is defined as sea ice that survives the summer melting, is generally thicker and more deformed than first-year ice. Therefore, the amount of multiyear ice significantly affects both the ice pack dynamics and the heat balance of the Arctic Ocean. Variations in the heat balance and ice transport can, in turn, cause changes in the amount of ice surviving the summer melt to become or remain as multi-year ice. Consequently, the ice surviving the summer melt is a significant indicator of the state of the ice pack and of changes that may be occurring, but the amount of ice that survives the summer melting has not been well determined.

Widely used indicators of ice surviving the summer melt have been the summer minimum (SM) 'ice extent' area and the minimum 'actual area' of sea ice, taking into account the open water in leads and polynyas within the pack. The ice extent is the area of the sea-ice pack with concentrations $\left(C_{\mathrm{T}}\right)$ greater than some threshold (typically $C_{\mathrm{T}}=10-15 \%$ ), and the actual area of sea ice is the spatial integral of $C_{\mathrm{T}}$ over the extent of the ice pack. $C_{\mathrm{T}}$, which is the total concentration of all ice types (i.e. first-year and multi-year), has been derived from satellite passive-microwave observations using various algorithms (Andersen and others, 2006). Of these two parameters, the actual area of sea ice $\left(A_{\mathrm{SM}}\right)$ at the $\mathrm{SM}$ is more relevant for determining the amount of multiyear ice that will be present in the subsequent fall and winter seasons. However, the area of surviving ice has not been well determined, because the time of the summer minimum varies significantly from region to region over the Arctic Ocean. Although comprehensive sea-ice thickness estimates are becoming available from satellite altimetric measurements (Laxon and others, 2003; Kwok and others, 2004; Zwally and others, 2008), this paper focuses on the widely used measurement of sea-ice area.

The SM ice area, $A_{\mathrm{SM}}$, as well as the SM ice extent, are commonly obtained from near-simultaneous (i.e. same day) satellite observations over the entire Arctic Ocean. However, meteorological conditions that drive the melt-freeze cycle vary widely from region to region, as well as interannually, which means that the transitions from melting to freezing, and therefore the local minima, do not occur simultaneously over the entire ice pack. Even in late September, the ice pack is usually melting in some places while ice is growing elsewhere. Consequently, the SM method overestimates the amount of ice surviving the summer melting for two reasons: (1) where the local meltfreeze transition occurs before the SM, new first-year ice is included in the SM area, as well as the ice that actually survives the summer melt to become multi-year sea ice; (2) where the melt-freeze transition occurs after the SM, some ice that does not survive summer is included in the SM area. Consequently, the commonly used SM method overestimates the area of ice surviving the summer melting due to melt-freeze transitions that occur either earlier or later than the summer minimum.

While the annual average sea-ice cover has been declining in recent decades (from 1979 to 2002 the decline was $\sim 0.36 \pm 0.05 \times 10^{6} \mathrm{~km}^{2}(10 \mathrm{a})^{-1}\left(3.0 \pm 0.4 \%(10 \mathrm{a})^{-1}\right)$, (Cavalieri and others, 2003)), the SM ice areas have been declining significantly faster $\left(7.7 \pm 3 \%(10 \mathrm{a})^{-1}\right.$ for $1979-2004$ according to Stroeve and others (2005), or $9.8 \pm 1.5 \%(10 a)^{-1}$ for 
1979-2005 according to Comiso (2006)). Such analyses of long-term sea-ice trends have been based on both ice extent and actual ice area, for which the long-term trends have been very similar even though significant interannual variations or short-term variations occur in their ratio, i.e. average sea-ice concentration and area of open water within the ice pack (Parkinson and others, 1999; Zwally and others, 2002). Estimates of multi-year ice concentration $\left(C_{\mathrm{pMY}}\right)$ during winter (e.g. Cavalieri and others, 1984; Gloersen and Cavalieri, 1986; Gloersen and others, 1992; Johannessen and others, 1999) have also been derived from passivemicrowave measurements. Johannessen and others (1999) showed the area of multi-year ice also decreased by $\sim 7 \%(10 \mathrm{a})^{-1}$ from 1978 to 1998 , which is generally consistent with the larger rate of decline in the SM ice area compared with the annual average.

An improved estimate of the area of ice surviving the summer melt to become multi-year ice is of interest for several reasons: (1) to compare trends in the amount of surviving ice with trends in conventional SM ice cover; (2) to characterize the spatial patterns of the minimum ice concentration and the timing of the minimum; (3) to provide a baseline for evaluation of various methods of observing multi-year ice during the winter; and (4) to provide data for comparison with sea-ice models of distributions of multiyear and other ice types. Therefore, the subjects of this paper are: (1) calculation of estimates of the actual area of ice surviving the summer melt to become multi-year ice using a new method; (2) an analysis of the interannual variability of multi-year ice (old and newly formed) and the variability of the average time of occurrence of the melt-freeze transition; and (3) analysis of the relationship of estimates from our method to the commonly used SM method and estimates of multi-year ice the following winter.

To estimate the area of ice that survives the summer melt, we use the concept of local temporal minimum (LTM) ice concentration to account for spatial variations in the timing of the melt-freeze transition (Gloersen and others, 1992). We use smoothed time series of $C_{\mathrm{LTM}}$ on $25 \mathrm{~km}$ grids to capture the time of transition from predominately melting to freezing on local spatial scales and estimate the area of ice surviving at the transition in each gridcell. The total area of ice surviving the summer melt $\left(A_{\mathrm{LTM}}\right)$ is given by spatial integration of $C_{\text {LTM }}$. We discuss various physical factors that may affect our estimates such as ice convergence/ divergence, advection and summer melt ponds.

\section{SEA-ICE CONCENTRATION MAPPING}

Figure 1 shows the mapped distributions of $C_{\mathrm{T}}$ for 24 years (1979-2002) for the day near the end of the melt season when the total integrated area of ice is at the SM, which varies from 5 September in 1987 to 1 October in 1995. The data are from the Nimbus 7 scanning multichannel microwave radiometer (SMMR) and Special Sensor Microwave/ Imager (SSM/I) (communication from User Services NSIDC (US National Snow and Ice Data Center)/CIRES (Cooperative Institute for Research in Environmental Sciences), nsidc@ nsidc.org). The NASA Team algorithm (Cavalieri and others, 1984, 1991, 1995; Gloersen and Cavalieri, 1986) is used to derive $C_{\mathrm{T}}$ and $C_{\mathrm{pMr}}$. Although a variety of different algorithms have been used to derive $C_{\mathrm{T}}$, all are essentially based on large differences in the microwave-emission properties of sea ice and open water. Although there are quantitative differences (Andersen and others, 2006) among algorithms, the essential characteristic of our results should be reproducible using other $C_{\mathrm{T}}$ algorithms. Daily sequences of such maps show that the ice edge continues to retreat after the SM in some regions, while the edge is advancing in other areas. Within the pack, the areas of high concentration (i.e. $>90 \%$ ) shown in Figure 1 vary with time as new ice is formed in various regions.

Figure 2 shows the corresponding monthly averaged maps of multi-year ice, $C_{\mathrm{pMY}}$, in the following Februaries, also derived using the NASA Team algorithm. During the winters of this period, the measured total ice area (first-year and multi-year) in the Arctic Ocean is $\sim 6.9 \times 10^{6} \mathrm{~km}^{2}$, and the estimated multi-year ice area $\left(A_{\mathrm{pMY}}\right.$, the integral of $\left.C_{\mathrm{pMY}}\right)$ is $\sim 3.0 \times 10^{6} \mathrm{~km}^{2}$ within the multi-year ice pack designated by $C_{\mathrm{pMY}} \geq 20 \%$. Based on these estimates, the first-year ice concentration is $\sim 32 \%$, the open water is $<2 \%$ and the average $C_{\mathrm{pMY}}$ within the multi-year ice pack in winter would be $\sim 66 \%$. However, a peculiarity of the estimates of $A_{\mathrm{pMY}}$ is the tendency to increase during winter (e.g. Gloersen and others, 1992; Johannessen and others, 1999), which is contrary to the definition of multi-year ice, suggesting that the microwave signature of multi-year ice continues to develop during fall and early winter and may not provide a measure of all the multi-year ice. Therefore, a residual discrepancy between the ice surviving the summer melt to become multi-year ice and the wintertime estimates of multi-year ice from passive-microwave algorithms should be expected. Although we provide a measure of this residual discrepancy, examination of deficiencies in passivemicrowave algorithms for multi-year ice is beyond the scope of this paper.

\section{CONCEPT OF LOCAL TEMPORAL MINIMUM (LTM) ICE CONCENTRATIONS}

Figure 3 illustrates our postulated evolution of ice types during the summer melt season and the subsequent freezing period. We consider local values of $C_{\mathrm{T}}(t)$ and $C_{\mathrm{MY}}(t)$ in areaelements of $25 \mathrm{~km}$ by $25 \mathrm{~km}$. $C_{\mathrm{MY}}(t)$ indicates the true area of multi-year ice to distinguish it from the passive-microwave estimate $C_{\mathrm{pMY}}(t)$. The $25 \mathrm{~km}$ scale is appropriate for this analysis, because it is larger than the size of ice floes and widths of leads, and sufficiently large to contain a locally representative set of ice types and open-water areas. Also, the environmental conditions (air temperature, radiation and wind fields) that force the ice melt/growth and the ice dynamics should be spatially coherent over areas of this size or larger.

After melting commences in spring, the area of open water increases as ice melts. The area of first-year ice should decrease faster than the area of the generally thicker multiyear ice. During the melt period, the rate of decrease in $C_{\mathrm{T}}$ varies with time as the forcing of the melting varies. As freezing and melting conditions alternate, the area of firstyear ice may either increase or decrease, but the effect on the area of multi-year ice should be a decrease until the transition from predominately melting to freezing occurs for the season. Net convergence or divergence of the ice pack also causes both $C_{\mathrm{T}}$ and $C_{\mathrm{MY}}$ to increase or decrease with time. Short-term $C_{\mathrm{T}}$ fluctuations, caused by ice convergence and divergence from short-term changes in the wind forcing, are not depicted in the figure. Our method uses data smoothing to average over such higher-frequency 
fluctuations, while retaining the longer-term net effect of convergence or divergence on the ice concentration.

The $C_{\mathrm{T}}$ reaches a minimum when local conditions change from predominately melting to freezing, at which time the remaining first-year ice becomes multi-year ice, by definition. (Although new multi-year ice is sometimes classified as second-year ice, we consider it to be a sub-category of multi-year ice, which is a more common usage.) We define this transition as the local temporal minimum (LTM) and note the time of its occurrence (TOO). The value of $C_{\mathrm{T}}$ at the LTM is $C_{\mathrm{LTM}}$. $C_{\mathrm{SM}}$ is defined to be the local concentration at the time of the overall SM, which is the time when the total area of the ice pack is at a minimum in daily-average maps, typically ranging from 5 September to 1 October. Generally, LTM should occur before the overall SM for much of the ice pack, except near the edge of the pack where melting may continue until late in the season. However, $C_{\mathrm{LTM}}$ is always less than or equal to $C_{\mathrm{SM}}$ by definition, even if $C_{\mathrm{SM}}$ occurs before $C_{\mathrm{LTM}}$.

After the LTM, the ice may again be subject to alternating periods of freezing and melting, during which $C_{\mathrm{T}}$ may increase or decrease. However, freezing must dominate after LTM, according to the definition of LTM. Otherwise, a new LTM and a lower value of $C_{\mathrm{LTM}}$ would occur. However, it is likely that some locations may have more than one nearminimum $C_{\mathrm{T}}$, with nearly equal values, separated in time by weeks or months.

The LTM method incorporates assumptions and/or approximations regarding dynamic and thermodynamic changes in the ice pack. The effects of ice convergence and divergence on determination of $C_{\text {LTM }}$ depend on the timescale of the changes with respect to ice melt/growth. Since the intent is to capture a local-scale snapshot of the minimum ice area remaining at the transition from predominately melting conditions to freezing conditions, clearly high-frequency short-term changes in the divergence/convergence on the order of days would cause systematic selection of values of $C_{\mathrm{LTM}}$ that are too small. Smaller values during times of divergent ice motion would tend to be selected, and the subsequent increases in $C_{\mathrm{T}}$ due to convergence would not be accounted for. Such short-term changes in the convergence and divergence with a frequency of several days are characteristic of synoptic weather systems and consequent short-term changes in the wind forcing. However, longer-term changes in $C_{\mathrm{T}}$ due to convergence or divergence of the pack do affect the area of ice surviving the summer melt.

The postulated evolution of $C_{\mathrm{T}}$ is examined by time-series analysis of observed $C_{\mathrm{T}}$ at each $25 \mathrm{~km}$ by $25 \mathrm{~km}$ map element. The time series are first temporally smoothed with a 12 day Gaussian smoother (12 day width at half-maximum) to prevent high-frequency dynamic changes (convergence and divergence) from obscuring the desired minima at the melt-freeze transition. The LTM is defined to be the minimum value of $C_{\mathrm{T}}$ in the smoothed time series. The 12 day smoothing is chosen to be long compared to typical wind-driven convergence/divergence events, and short compared to the length of the summer melt period.

An example of the temporal $C_{\mathrm{T}}$ signal before and after smoothing is shown in Figure $4 \mathrm{a}$ and $\mathrm{b}$ for the gridcell at $76.6^{\circ} \mathrm{N}, 158.5^{\circ} \mathrm{W}$ and for the 2 year period January 1980 to December 1981 . The observed $C_{\mathrm{T}}$ follows the postulated evolution, including a slower rate of decline during the melt season and a faster rate of rise after the $C_{\mathrm{LTM}}$ is reached. The reduction in ice concentration from melting of ice of various thicknesses is generally slower than the increase in concentration from the freezing of new thin ice after the melt-freeze transition. Figure $4 \mathrm{c}$ shows the average surface temperatures for that grid location during that time period (obtained from the European Centre for Medium-Range Weather Forecasts (ECMWF)). Note that $C_{\mathrm{LTM}}$ is reached very close to the time that the surface temperature drops to the freezing point after several months of summer melting in both years. In this example, $C_{\mathrm{LTM}}$ also occurs before $C_{\mathrm{SM}}$, but it could occur later. This sequence of events clearly follows our postulated evolution of the ice concentration.

The unsmoothed $C_{\mathrm{T}}$ data in Figure 4 show short-term fluctuations of roughly $\pm 5 \%$ compared to the smoothed $C_{\mathrm{T}}$, which are consistent with a typical divergence/convergence rate $1 \% \mathrm{~d}^{-1}$ (Hibler, 1974) and short-term dynamic fluctuations associated with synoptic weather systems (Thorndike and Colony, 1982; Zwally and Walsh, 1987). However, persistent net changes in $C_{\mathrm{T}}$ due to a net convergence or divergence during the averaging period affect the amount of ice surviving the summer melt and should be captured in the locally selected $C_{\text {LTM }}$. Similar results are obtained using 6 or 9 day running averages of $C_{\mathrm{T}}$, so the selected $C_{\mathrm{LTM}}$ is not very sensitive to the particular smoothing method.

Ice advection also affects $C_{\mathrm{T}}(t)$, because our analysis elements are spatially fixed rather than moving with the ice pack. For example, an advection of $5 \mathrm{~km} \mathrm{~d}^{-1}$ moves the ice through about three $25 \mathrm{~km}$ map elements in 15 days, but this affects our results only if the ice behavior in nearby elements is significantly different. The time evolution of $C_{\mathrm{T}}(t)$ for three locations separated by $\sim 300 \mathrm{~km}$ is shown in Figure 5 , described in the next section. The time evolution of $C_{\mathrm{T}}(t)$ during the summer is very similar for the three locations, but the $C_{\mathrm{LTM}}$ are quite different. Around their LTM in particular, the ice pack was drifting $\sim 5 \mathrm{~km} \mathrm{~d}^{-1}$. Locations $\mathrm{A}$ and $\mathrm{B}$, separated by $\sim 100 \mathrm{~km}$, have nearly identical TOO and low $C_{\mathrm{LTM}}$, reflecting their proximity to the edge of the Septemberminimum ice pack. Location C, which is $\sim 200 \mathrm{~km}$ farther into the ice pack, has an earlier LTM by $\sim 15$ days and a larger $C_{\mathrm{LTM}}$. Therefore, even though the pack is moving, the times of the LTM and the values of $C_{\mathrm{LTM}}$ appear to be determined by the respective local conditions around the time of their LTM. For this paper, we assume residual advection effects on the determination of $C_{\mathrm{LTM}}$ are small, at least in large-area averages. In the future, a more sophisticated analysis utilizing ice motion fields to track specific ice areas can be used.

Thermodynamically, ice growth during the smoothing period would cause the smoothed $C_{\text {LTM }}$ to overestimate by a small amount the amount of ice surviving the summer. The overestimate would be about half the increase in ice area due to freezing during the averaging period. However, melting during the smoothing period would cause an opposite effect on each local estimate, reducing the bias. Possible biases due to this effect would be further reduced in spatial averages. After LTM occurs, small amounts of the multi-year ice may melt during reversals of the freezing trend, thereby causing overestimates in the amount of ice surviving the summer melt. However, such melting is likely to be very small, because new ice would be more vulnerable than old ice, and significant melting of the new ice would produce a new minimum. Generally, the relatively fast increase in concentration due to the rapid formation of new ice after the meltfreeze transition helps selection of the proper $C_{\mathrm{LTM}}$. 
23 Sep 1979

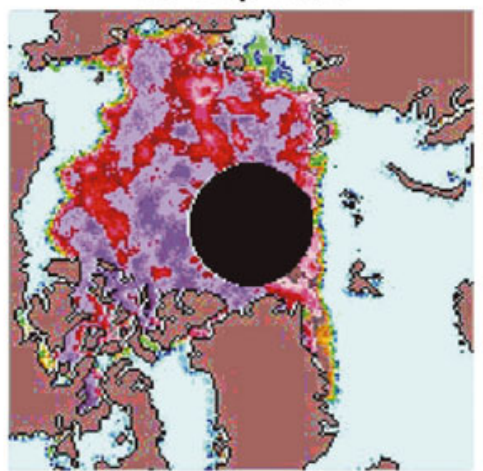

09 Sep 1980

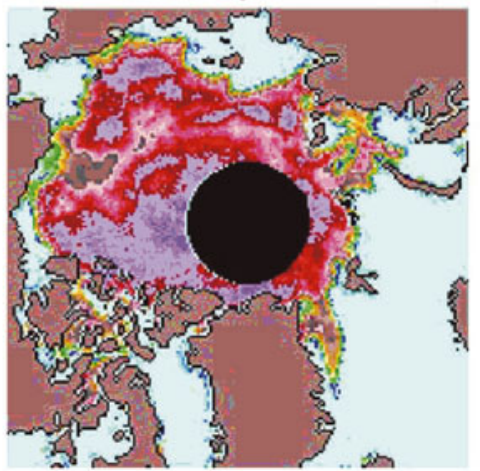

12 Sep 1981

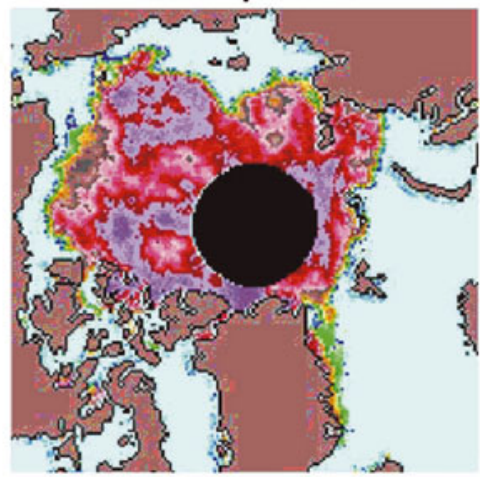

17 Sep 1982

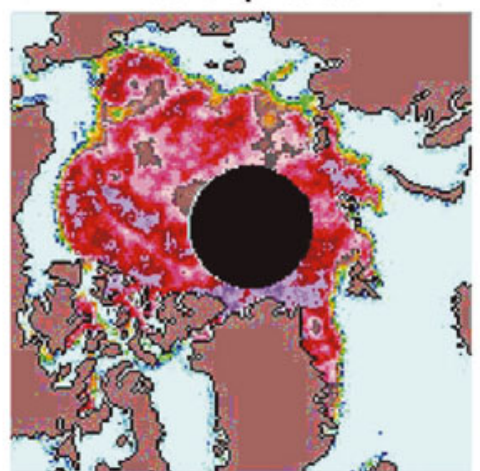

06 Sep 1983

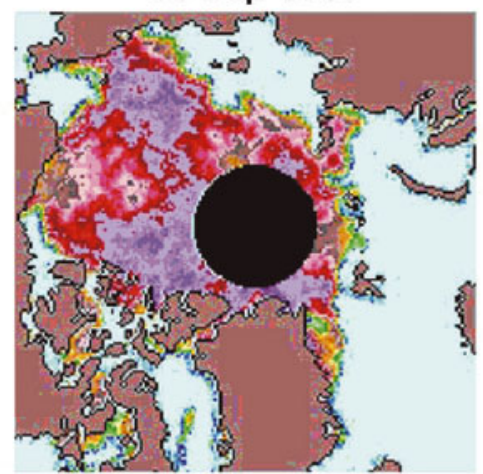

16 Sep 1984

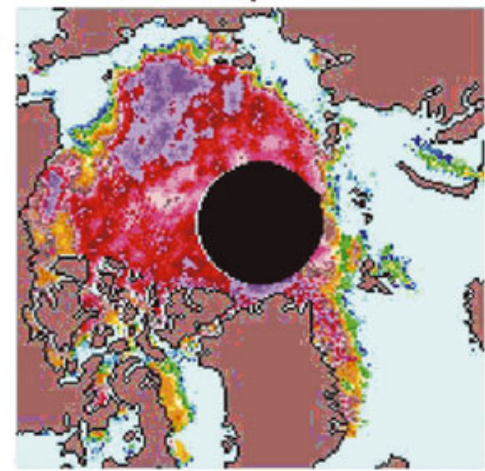

13 Sep 1985

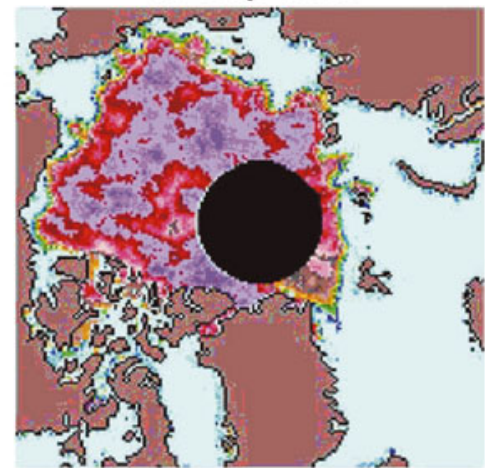

14 Sep 1986

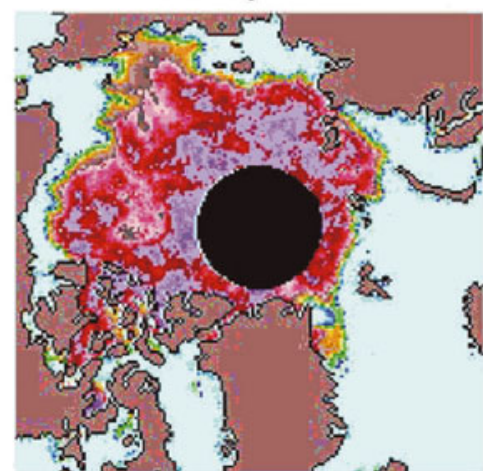

05 Sep 1987

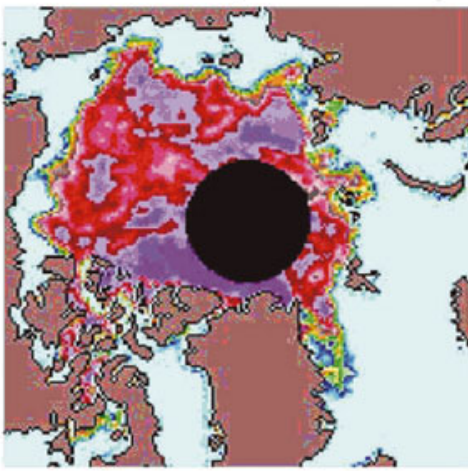

09 Sep 1988

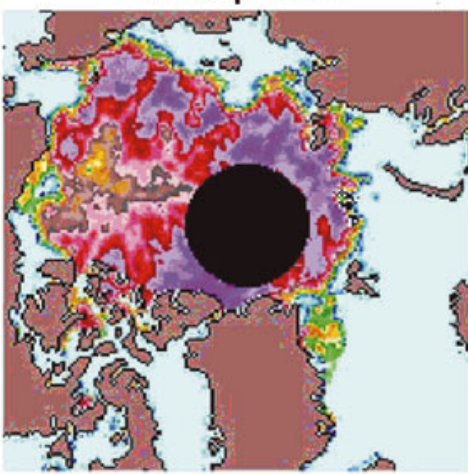

20 Sep 1989

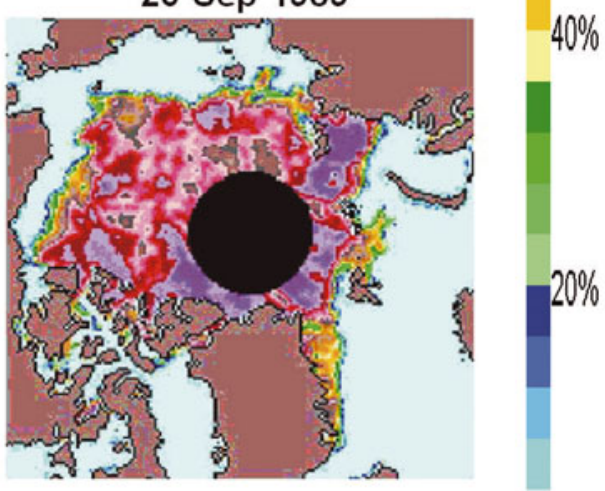

17 Sep 1990

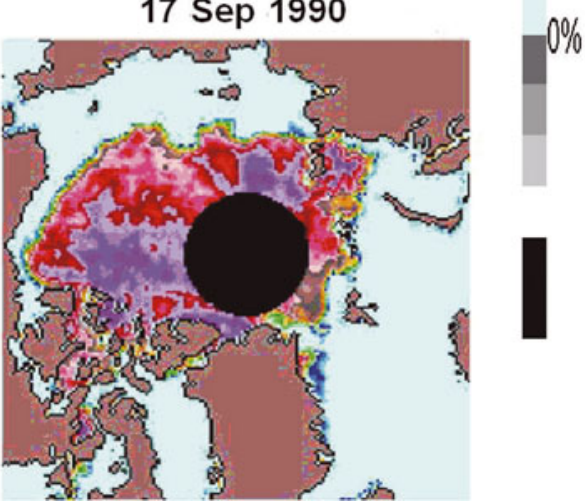

Fig. 1. Sea-ice concentrations (1979-2002) on the day of the summer minimum (SM), usually in mid-September. Estimates of the area of ice surviving the summer melting to become multi-year ice calculated from these daily maps are too large, because of the inclusion of new firstyear ice within the pack and later loss of ice near the ice edge.

EFFECT OF MELT PONDS ON $C_{\mathrm{T}}(T), C_{\mathrm{LTM}}$ AND $A_{\mathrm{LTM}}$

Open water in melt ponds on ice floes affects the passivemicrowave determinations of $C_{\mathrm{T}}(t)$, because non-frozen melt ponds and open water in leads and polynyas have similar microwave signatures (Carsey, 1985; Gogineni and others, 1992), and can in principle affect both $A_{\mathrm{LTM}}$ and $A_{\mathrm{SM}}$. For our purposes, the relevant questions are: (1) how does the fractional area of unfrozen melt ponds compare to the area of open water in leads and polynyas at the melt-freeze 


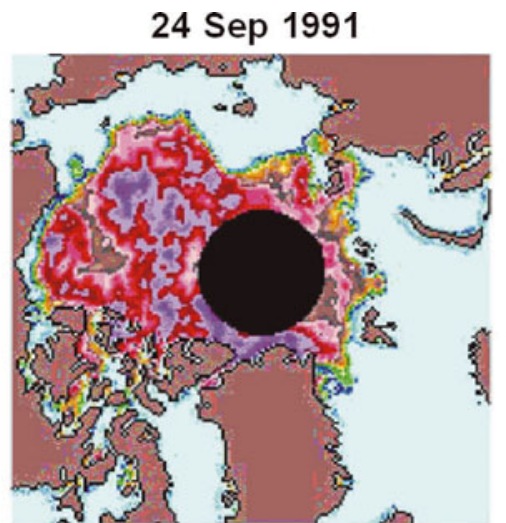

06 Sep 1992

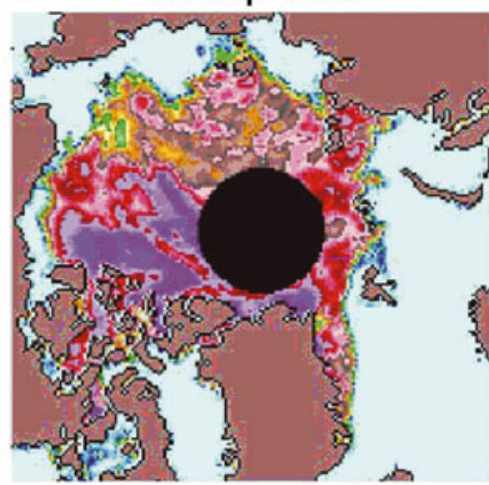

13 Sep 1993

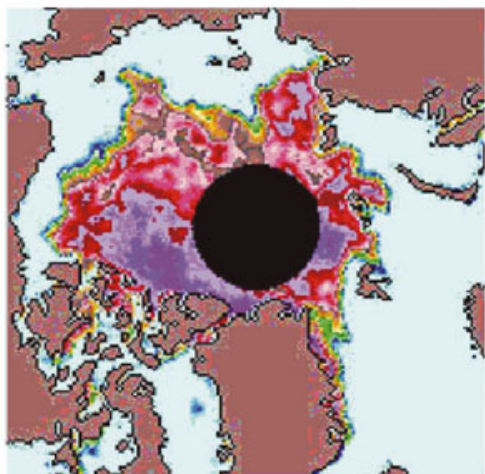

12 Sep 1994

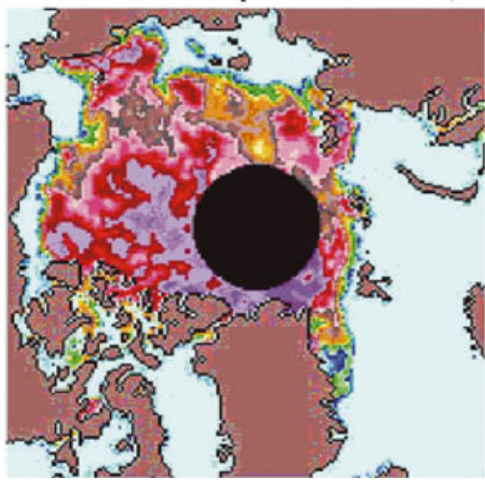

01 Oct 1995

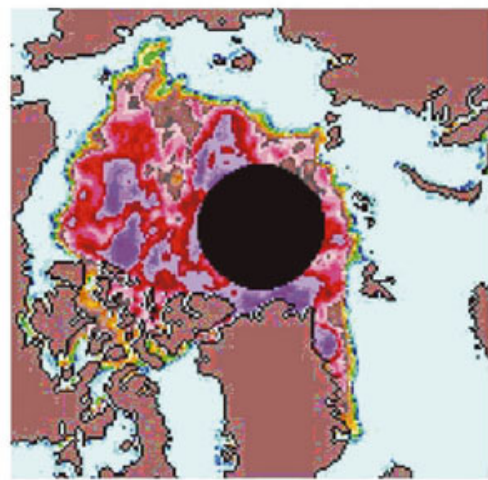

13 Sep 1996

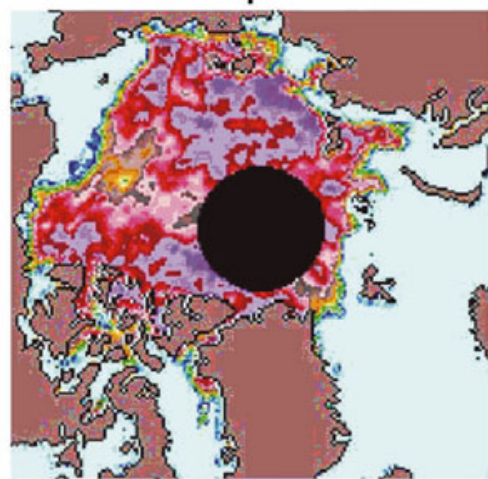

28 Sep 1997

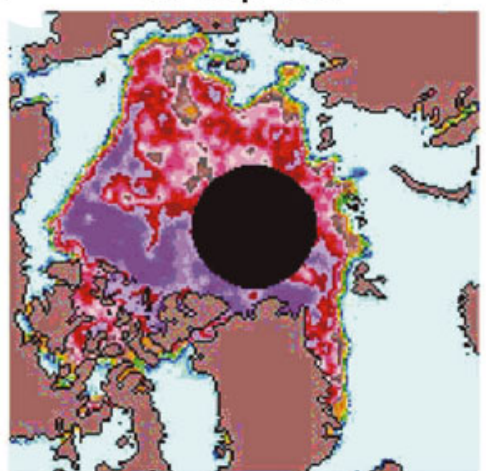

17 Sep 1998

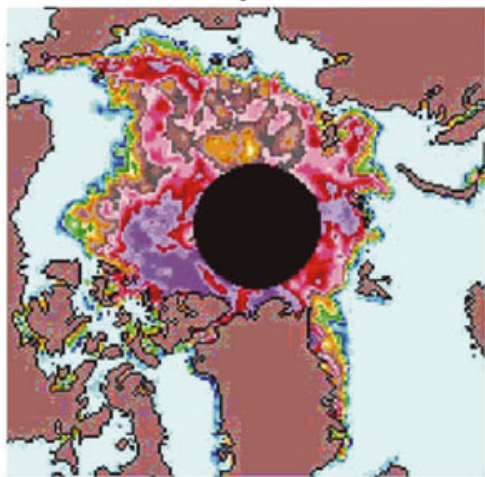

08 Sep 1999

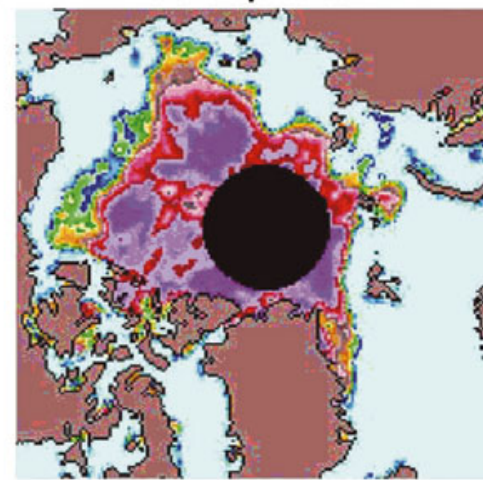

14 Sep 2000
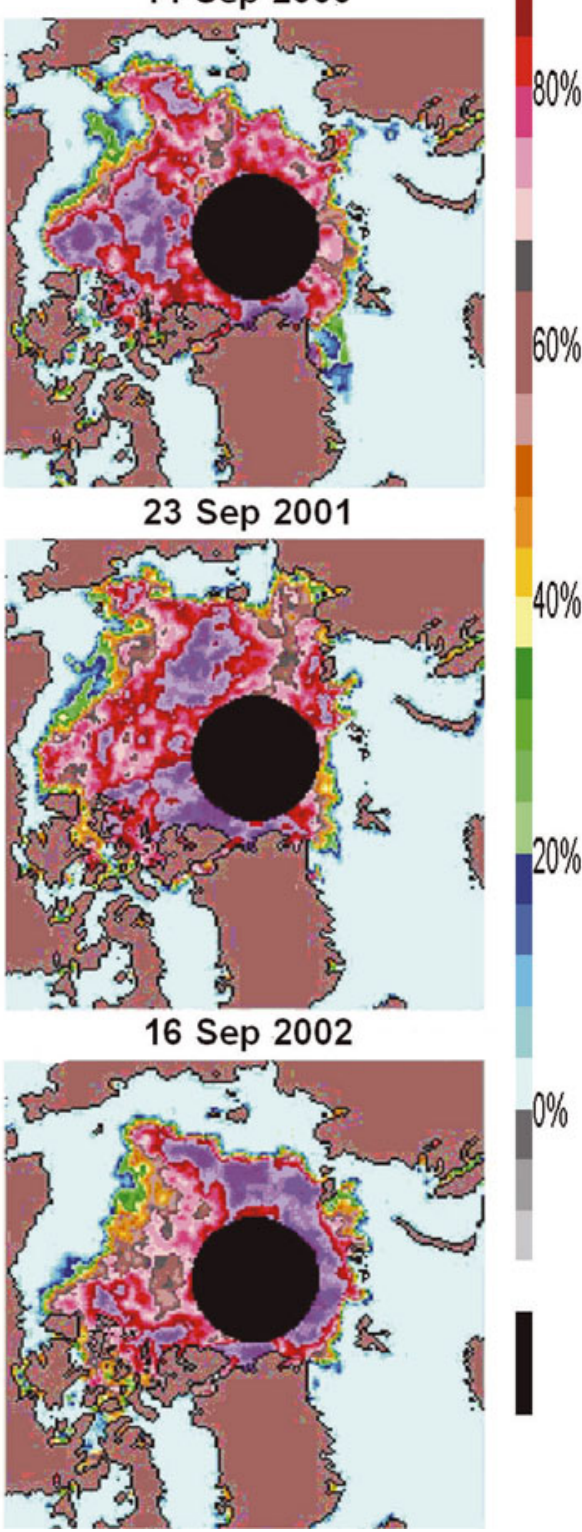

Fig. 1. (continued)

transition in late summer when $C_{\mathrm{LTM}}$ is selected? and (2) is the area of melt ponds plus the area of leads and polynyas over the $25 \mathrm{~km}$ cells at some time prior to the melt-freeze transition greater than the area of open water in leads and polynyas at the melt-freeze transition?

Firstly, the areal coverage of unfrozen melt ponds tends to peak in early to mid-summer and decline by the TOO of the melt-freeze transition when $C_{\mathrm{LTM}}$ is selected. As shown below (Figs 8 and 9), the average TOO over the ice pack ranges from about 6 to 28 August. In the Beaufort Sea, melt ponds typically cover $20-50 \%$ of the floes in early July, and decrease to $\sim 12 \%$ coverage by 3 August (fig. 12 in Fetterer and Untersteiner, 1998). Also, as the pond coverage on thick ice decreases with time, the coverage on thin ice increases 

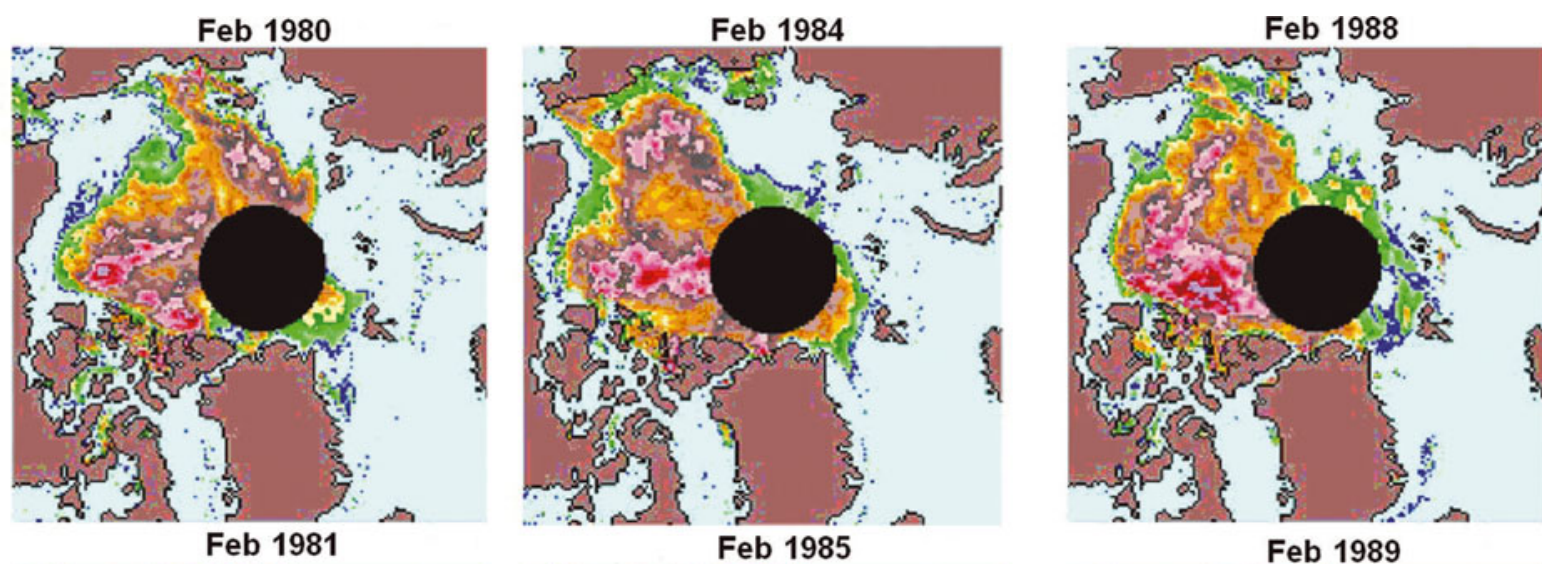

Feb 1988

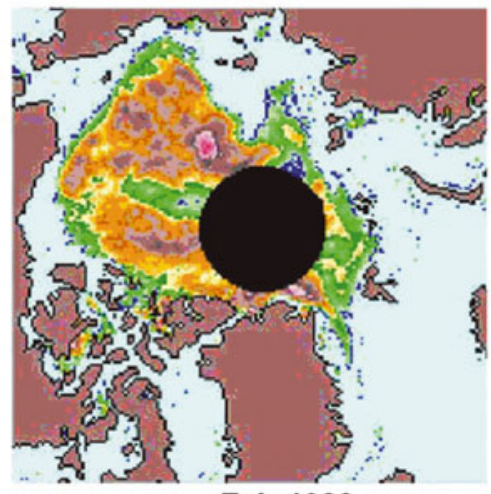

Feb 1982

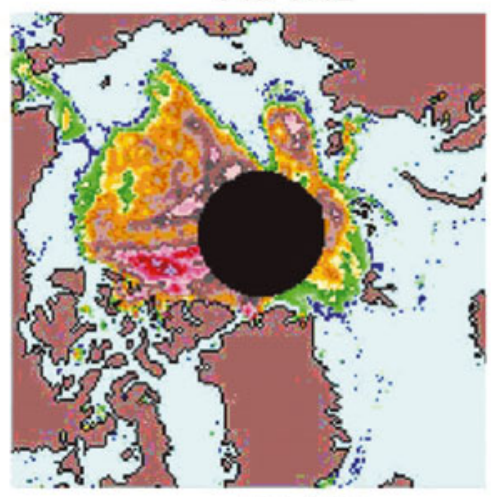

Feb 1983

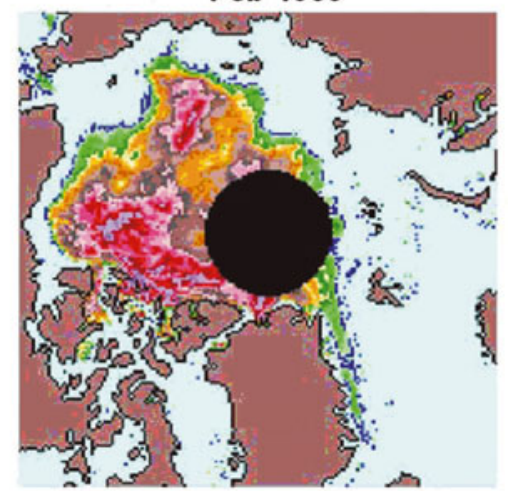

Feb 1986

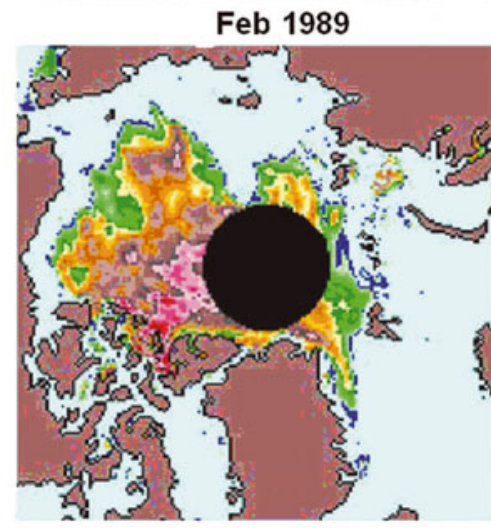

$100 \%$

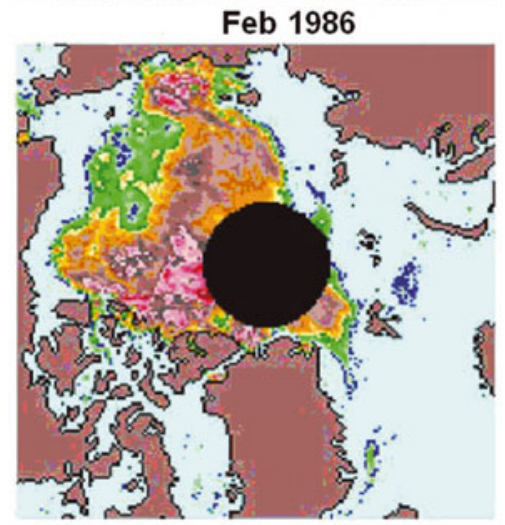

Feb 1987
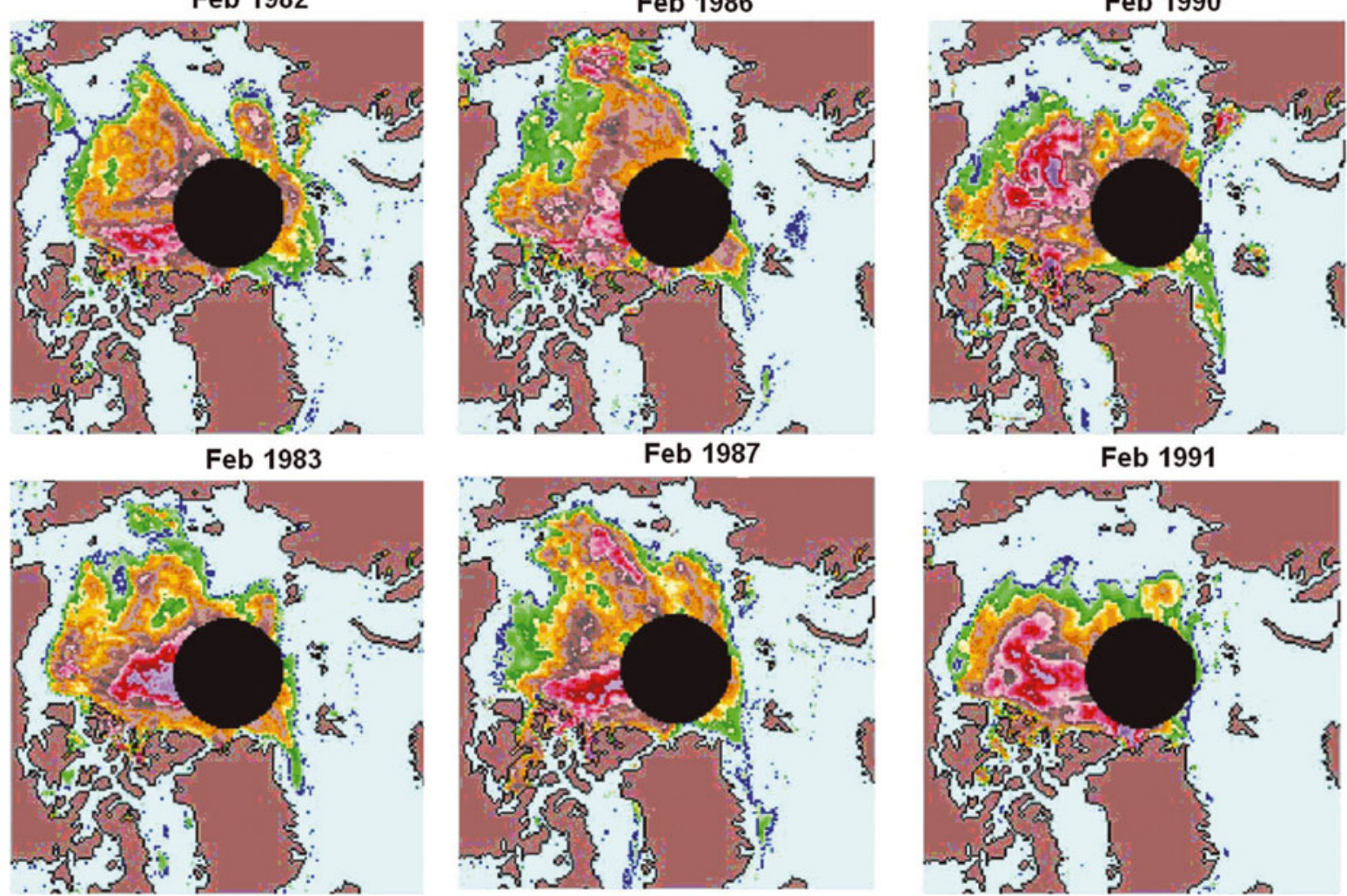

Feb 1991

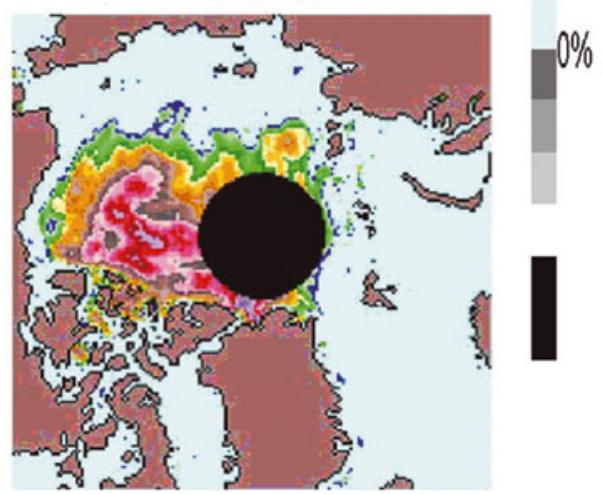

Fig. 2. Monthly averaged multi-year sea-ice concentrations $\left(C_{\mathrm{pMY}}\right)$ in February 1979-2002, from a passive-microwave algorithm that appears to underestimate the true area of multi-year ice.

with time, leading to the disappearance of thin ice at the end of the summer (Fetterer and Untersteiner, 1998). Perovich and others (2002) show similar results in the vicinity of the SHEBA (Surface Heat Budget of the Arctic Ocean) site in the Beaufort Sea, with melt ponds covering $\sim 20 \%$ of the area from 18 June until 7 August 1998, after which the pond area dropped sharply to $2 \%$ by 22 August. Secondly, while the area of melt ponds is decreasing, the open water in leads and polynyas is generally increasing as more sea ice melts and the ice pack thins during the summer melting (e.g. Thorndike and others, 1975; Perovich and others, 2002). Perovich and others (2002) show a lead area of $5 \%$ on 
Feb 1992

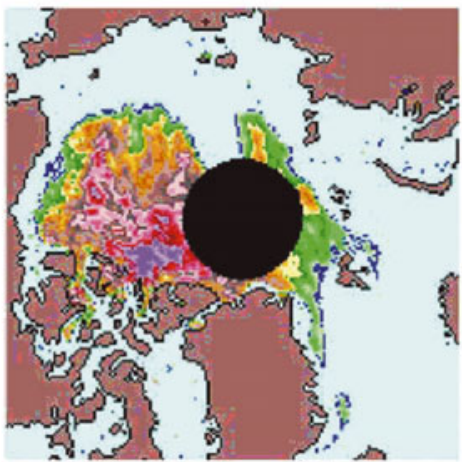

Feb 1993

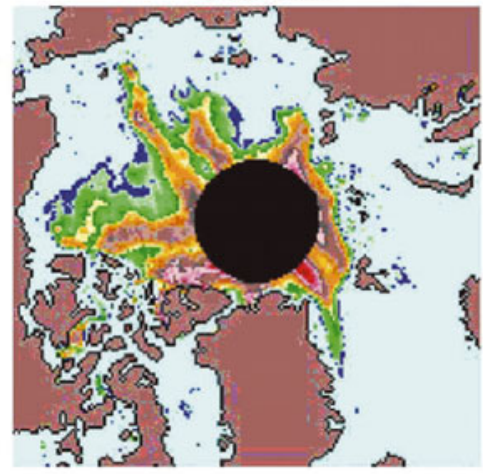

Feb 1994

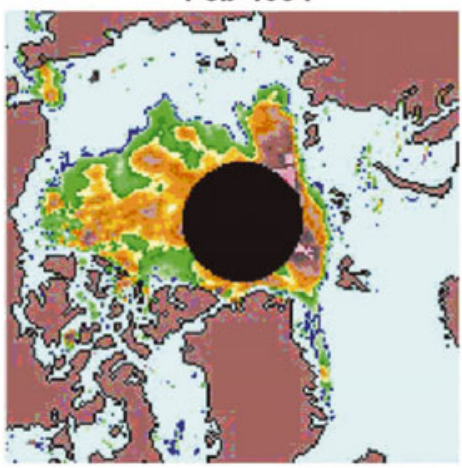

Feb 1995

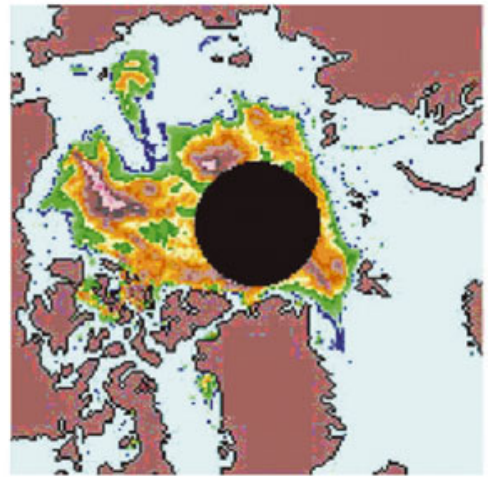

Feb 1996

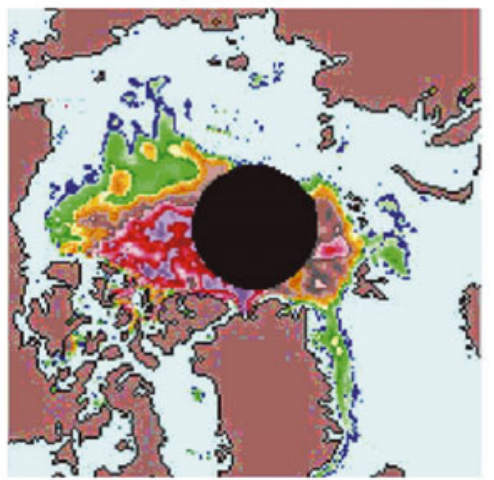

Feb 1997

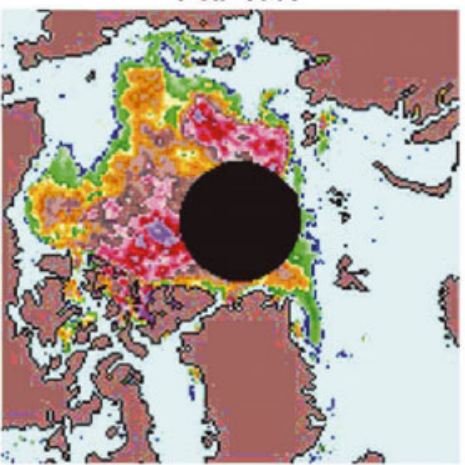

Feb 1998

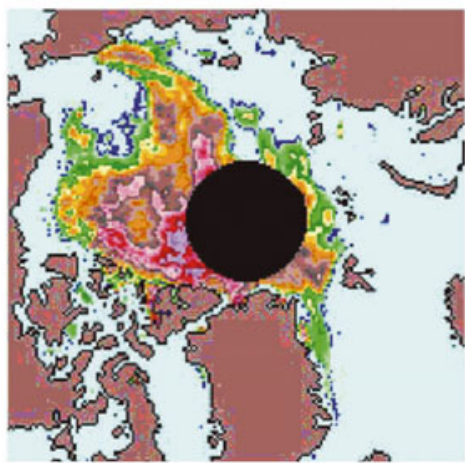

Feb 1999

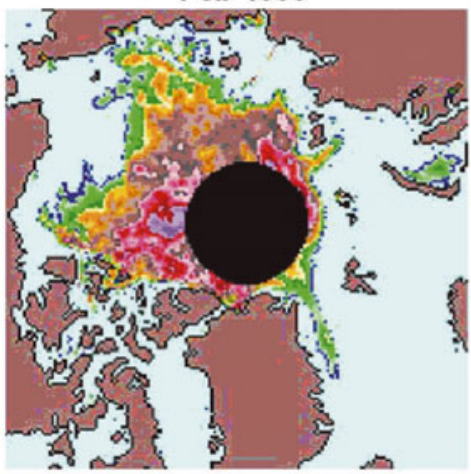

Feb 2000

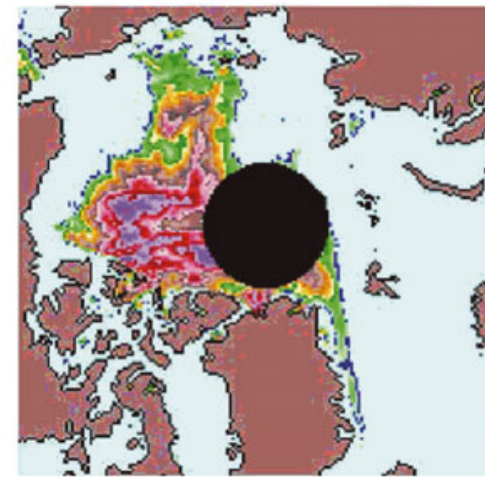

Feb 2001

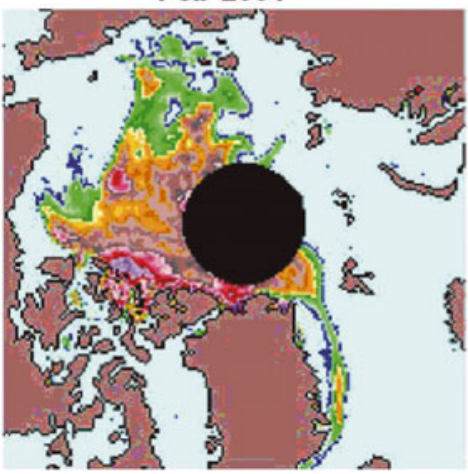

Feb 2002

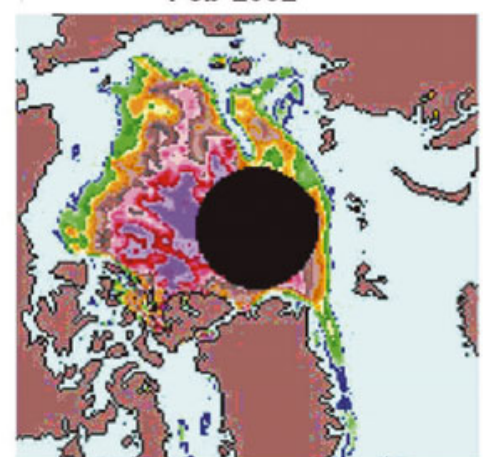

$40 \%$

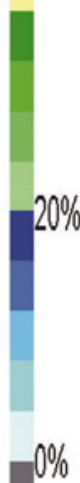

Feb 2003

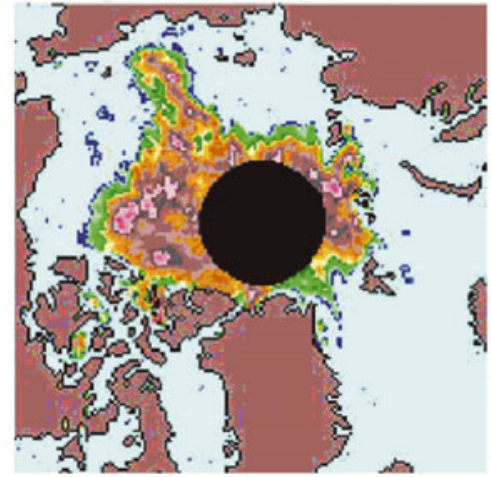

Fig. 2. (continued)

25 July rising to $18 \%$ on 7 and 22 August. Thirdly, melt ponds have lower salinity than ocean water and therefore freeze before the open ocean water in leads and polynyas, as shown for example in figure $3 \mathrm{e}$ of Perovich and others (2002), where the ponds are mostly covered with ice while the leads and polynyas remain as open water. As melt ponds freeze, their emissivity quickly becomes similar to that of completely frozen ponds (Gogineni and others, 1992).

The evolution of $C_{\mathrm{T}}(t)$ in the vicinity of the measurements of melt ponds by Perovich and others (2002) is shown in Figure 5. At location $\mathrm{A}\left(77^{\circ} 24.2^{\prime} \mathrm{N}, 166^{\circ} 31.2^{\prime} \mathrm{W}\right)$ on 15 June, the melt-pond fraction was $4.4 \%$ measured along a box of 


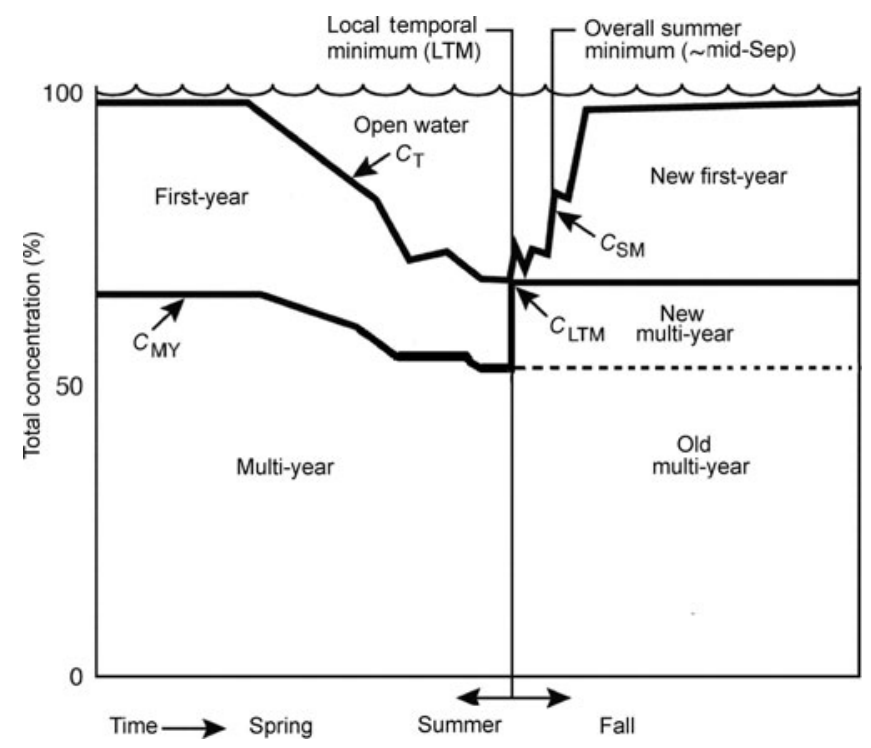

Fig. 3. Schematic of the evolution of first-year and multi-year ice concentrations during the summer melt season for a typical single map element. The local transition from predominately melting to freezing conditions is defined as the local temporal minimum (LTM), at which time the remaining first-year ice becomes new multi-year ice along with the multi-year ice from the previous year. The concentration $\left(C_{\mathrm{LTM}}\right)$ at the LTM represents the ice surviving the summer melt season. Most LTM, but not all, occur before the time of the overall summer minimum of all ice types over the total ice pack. In this case, $C_{S M}$ is greater than $C_{\mathrm{LTM}}$ because it includes some new first-year ice. High-frequency concentration variations caused by short-term fluctuations in convergence and divergence of the ice pack are not depicted.

$50 \mathrm{~km}$ flight-lines and it increased to $19.4 \%$ in a nearby vicinity on 18 June. The corresponding lead fraction was $3.1 \%$ for both periods, giving combined water fractions of $7.5 \%$ and $22.5 \%$ on the respective dates from the field measurements. However, $C_{\mathrm{T}}(t)$ on 18 June around location $\mathrm{A}$ was $93 \%$, indicating a microwave sensing of only $7 \%$ open water over an area of $25 \mathrm{~km}$ by $25 \mathrm{~km}$. This difference between the field and the satellite water fractions on 18 June could be due to sensing of somewhat different locations; $C_{\mathrm{T}}(t)$ did drop to $85 \%$ during the following 25 days. However, after 12 July, $C_{\mathrm{T}}(t)$ dropped much below the $77 \%$ that could be explained by the $\sim 23 \%$ pond and lead fraction indicated by the field measurements. During this period, the location of the field measurements was drifting northward, reaching location $B\left(78^{\circ} 15.9^{\prime} \mathrm{N}, 165^{\circ} 56.3^{\prime} \mathrm{W}\right)$ by 22 August when the pond fraction had dropped to $2.0 \%$ and the lead fraction had risen to $18.2 \%$. However, the $C_{\mathrm{T}}(t)$ at location B on 22 August had dropped to $50 \%$, indicating $50 \%$ total water fraction compared to the $20.2 \%$ suggested by the field measurements. Therefore, the satellite $C_{\mathrm{T}}(t)$ indicates a significantly lower sea-ice concentration and more open ocean water at this location near the end of the summer than could possibly be explained by the effect of melt ponds on the satellite-based $C_{\mathrm{T}}(t)$.

Furthermore, and even more importantly, the $C_{\text {LTM }}$ for these locations, $\mathrm{A}$ and $\mathrm{B}$, are not reached until $\sim 30$ days after most of the melt ponds have frozen. Locations $A$ and $B$ are also relatively close to the edge of the summer ice pack, which explains their relatively low $C_{\text {LTM }}$ values of $11 \%$ and $40 \%$, respectively. By 4 October the site of the field
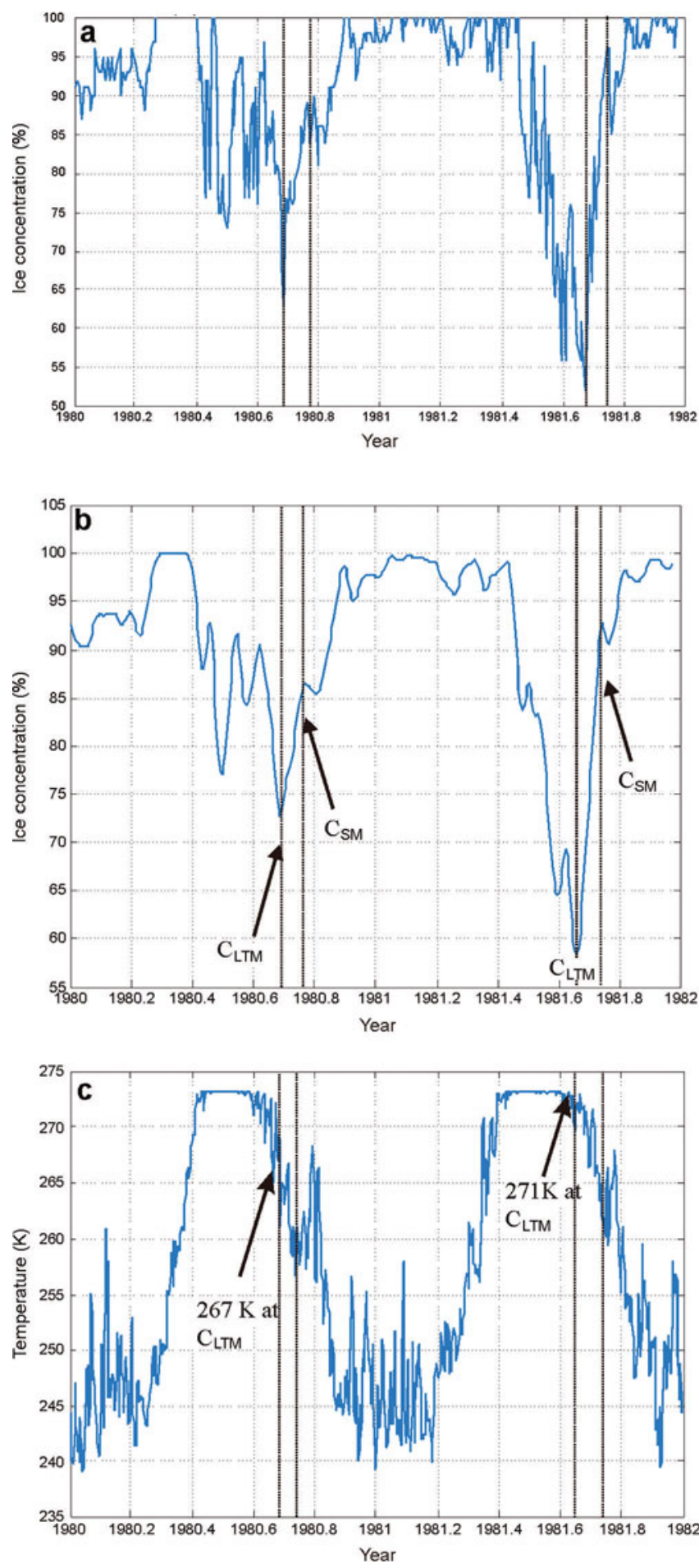

Fig. 4. Evolution of the sea-ice concentration over a 2 year period in a $25 \mathrm{~km}$ map element at $76.6^{\circ} \mathrm{N}, 158.5^{\circ} \mathrm{W}$. (a) Observed ice concentrations, $C_{\mathrm{T}}(t)$. (b) Observed ice concentrations smoothed with a 12 day Gaussian. (c) Surface air temperatures at that element from ECMWF. The times of the $C_{\mathrm{LTM}}$ and SM concentration $\left(C_{\mathrm{SM}}\right)$ at this location are, respectively, 5 and 9 September in 1980 and 28 August and 12 September in 1981. Note that the LTM occurs near the end of the melting period, when the open water in leads and polynyas begins to refreeze, as indicated by the air temperatures, and the SM occurs after the LTM.

measurements had drifted farther north to location $\mathrm{C}$ $\left(80^{\circ} 8.0^{\prime} \mathrm{N}, 166^{\circ} 16.0^{\prime} \mathrm{W}\right)$ where $C_{\mathrm{T}}(t)$ had increased to $83 \%$ from its $C_{\text {LTM }}$ minimum of $63 \%$ on 6 September. This $C_{\text {LTM }}$ occurred before the SM on 17 September when $C_{S M}$ was 
$70 \%$, indicating that $\sim 7 \%$ new ice is included in the SM ice area at this location. At the more southerly locations $A$ and $B$, the LTMs occur before the SMs, and the $C_{\mathrm{LTM}}$ compared to the $C_{\mathrm{SM}}$ also indicate $\sim 7-9 \%$ ice area that did not survive the summer would be included in the $A_{\mathrm{SM}}$ at these locations.

To summarize the discussion of the first question, while the melt-pond area is generally decreasing toward the late summer, the area of ocean water is increasing at the same time and the true ice concentration is decreasing toward its minimum value that the LTM is intended to capture. Also, at the time of the melt-freeze transition, after which the sea-ice concentration increases, the low-salinity melt ponds on the ice floes should have already been frozen and therefore have minimal effect on the selected $C_{\mathrm{LTM}}$. This interpretation is supported by the data in Figure 4 that show the $C_{\mathrm{LTM}}$ minimum at the end of the melt season when the temperature drops to freezing rather than a lower $C_{\mathrm{T}}(t)$ early in the melt season when the melt-pond fraction is high.

Regarding the second question, examination of numerous time series (such as those in Figs $4 \mathrm{~b}$ and 5) shows that the $C_{\mathrm{LTM}}$ minimum is usually at the end of the summer period of decreasing $C_{\mathrm{T}}(t)$ as postulated in Figure 3, followed by a more rapid rise in $C_{T}(t)$ during fall. This behavior is also shown by the distribution of TOO (Fig. 8) and the average TOO with time. While there are examples of multiple near-minima in $C_{\mathrm{T}}(t)$ and examples of selections of an earlier summer minimum, which could be affected by melt ponds, such cases are very few and should have only a small effect on the overall results. An example of multiple near-minima is in the passive-microwave $C_{\mathrm{T}}(t)$ from May to September averaged over a $150 \mathrm{~km}$ square area ( 36 of our cells) in figure 14 of Fetterer and Untersteiner (1998), which shows nearly equal minima of $75 \%$ and $73 \%$ in June and July before the final minimum of $75 \%$ in August. An estimate of the error in our results caused by such earlier selections is given by noting that earlier minima in our time series appear to be selected $<10 \%$ of the time and the selected $C_{\mathrm{LTM}}$ are mostly within $\sim 5 \%$ of the later minima. Therefore, the error in the spatially averaged $C_{\mathrm{LTM}}$ and in $A_{\mathrm{LTM}}$ should be less than a few percent.

Another indication that the effect of melt ponds is not dominating our results is given by the increasing trend in TOO (i.e. a later melt-freeze transition) along with the decreasing trends in ice area (both $A_{\mathrm{LTM}}$ and $A_{\mathrm{SM}}$ ), as we show in a following section. Presuming there would also be an increasing trend toward earlier melt-pond formation as the summer melt season lengthens, that effect would tend to cause a decreasing trend in TOO if melt ponds were in fact dominating the selection of $\mathrm{TOO}$, in contrast to what we observe.

\section{MAPS OF $C_{\mathrm{LTM}}$ AND TOO AND CALCULATION OF THE AGGREGATE LTM SEA-ICE AREAS AND THE TOTAL ICE AREA AT SM}

The $C_{\mathrm{LTM}}$ values calculated for each map element are shown in Figure 6 for each of the 24 years, and the corresponding TOO are shown in Figure 7. Histograms of TOO calculated over the perennial ice pack, defined as the region for which $C_{\mathrm{LTM}} \geq 10 \%$, are given in Figure 8 , along with the average TOO over the same region and the time of the overall SM. Figure 8 shows that the LTM mostly occur before the overall September minima $\left(C_{\mathrm{SM}}\right)$ in the ice-pack area, but some do occur later in locations that are mostly near the ice edge at the end of the melt season.

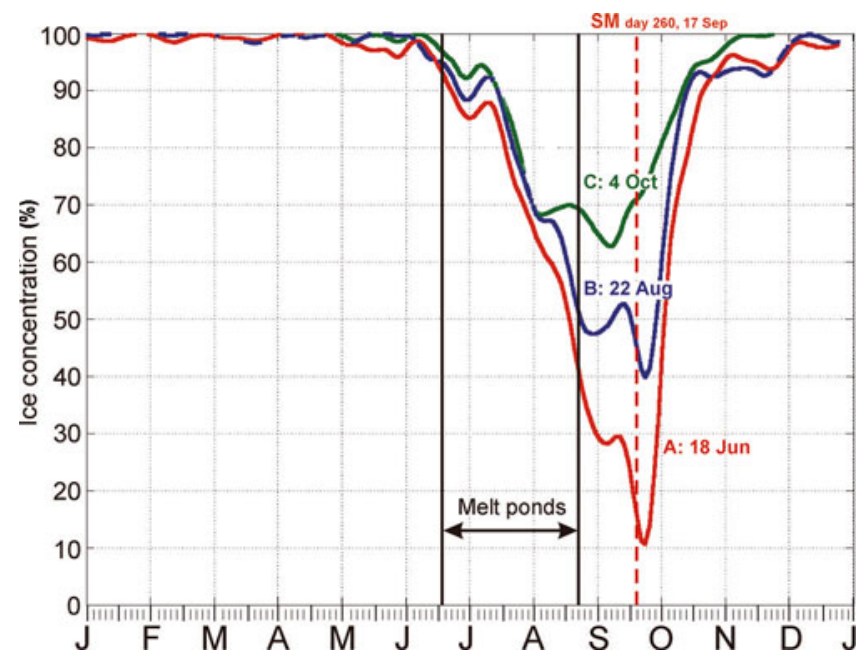

Fig. 5. Evolution of sea-ice concentration, $C_{\mathrm{T}}(t)$, during 1998 at three $25 \mathrm{~km}$ map elements in the northern Beaufort Sea where melt ponds were measured (Perovich and others, 2002). Melt ponds with $\sim 20 \%$ areal coverage appeared around location A $\left(77^{\circ} 24^{\prime} \mathrm{N}\right.$, $166^{\circ} 31^{\prime} \mathrm{W}$ ) on about 18 June, remained open through mid-August and became mostly frozen by 22 August when the field site had drifted northward to location B $\left(78^{\circ} 16^{\prime} \mathrm{N}, 165^{\circ} 56^{\prime} \mathrm{W}\right)$. The $C_{\mathrm{LTM}}$ at these locations, and at location $\mathrm{C}\left(80^{\circ} 8^{\prime} \mathrm{N}, 166^{\circ} 16^{\prime} \mathrm{W}\right)$ where the field site was located on 4 October, all occurred after the melt ponds were mostly frozen. The $C_{\mathrm{T}}(t)$ series at the three locations are very similar in the early season during the period of the melt ponds, but near the end of the summer are dominated by their relative distances from the edge of the minimum summer ice pack.

Year-by-year comparison of the distributions of $C_{\mathrm{LTM}}$ in Figure 6 with the distributions of $C_{S M}$ in Figure 1 shows some striking differences in both the lesser extent of the LTM pack in the seasonal ice zone and the lower concentrations within the LTM pack compared to the SM pack. As noted earlier, $C_{\mathrm{LTM}}$ is always less than or equal to $C_{\mathrm{SM}}$, whether the LTM is before or after the SM. Areas in the seasonal ice zone that have no ice cover at some time during the summer correctly have zero $C_{\mathrm{LTM}}$. In contrast, $C_{\mathrm{SM}}$ show non-zero values over large areas of the seasonal ice zone, clearly indicating that the SM method includes areas in which no ice survived the summer melt. That effect occurs because the ice edge is still retreating in some regions at the time of the SM while it is already advancing in others. Also, within the ice pack, the large patches of $C_{\mathrm{SM}}$ concentrations $>90 \%$, for example, (Fig. 1) include significant areas of new first-year ice. The large interannual variability of the locations of these highconcentration patches at the SM is an indication of the large spatial variability of the timing of new ice formation within the ice pack. Therefore, $A_{\mathrm{LTM}}$ (spatial integral of $C_{\mathrm{LTM}}$ ) is smaller than $A_{\mathrm{SM}}$ (spatial integral of $C_{\mathrm{SM}}$ ) in both the seasonal sea-ice zone, mainly due to late season melting, and within the pack, mainly due to new ice formation before the SM.

In Figure 7, the TOO of the LTM in the outer parts of the seasonal ice zone are early in the melt season, for example during the latter part of May (days 140-152) in the southern Barents Sea. In the inner part of the seasonal ice zone, near the edge of the remaining summer ice pack, the TOO of the LTM are near the end of the melt season, typically about the end of September (day 272), marking the end of the shrinking ice extent.

Within the perennial ice pack described by non-zero $C_{\mathrm{LTM}}$ in Figure 7, the TOO of the LTM tend to be earlier at 

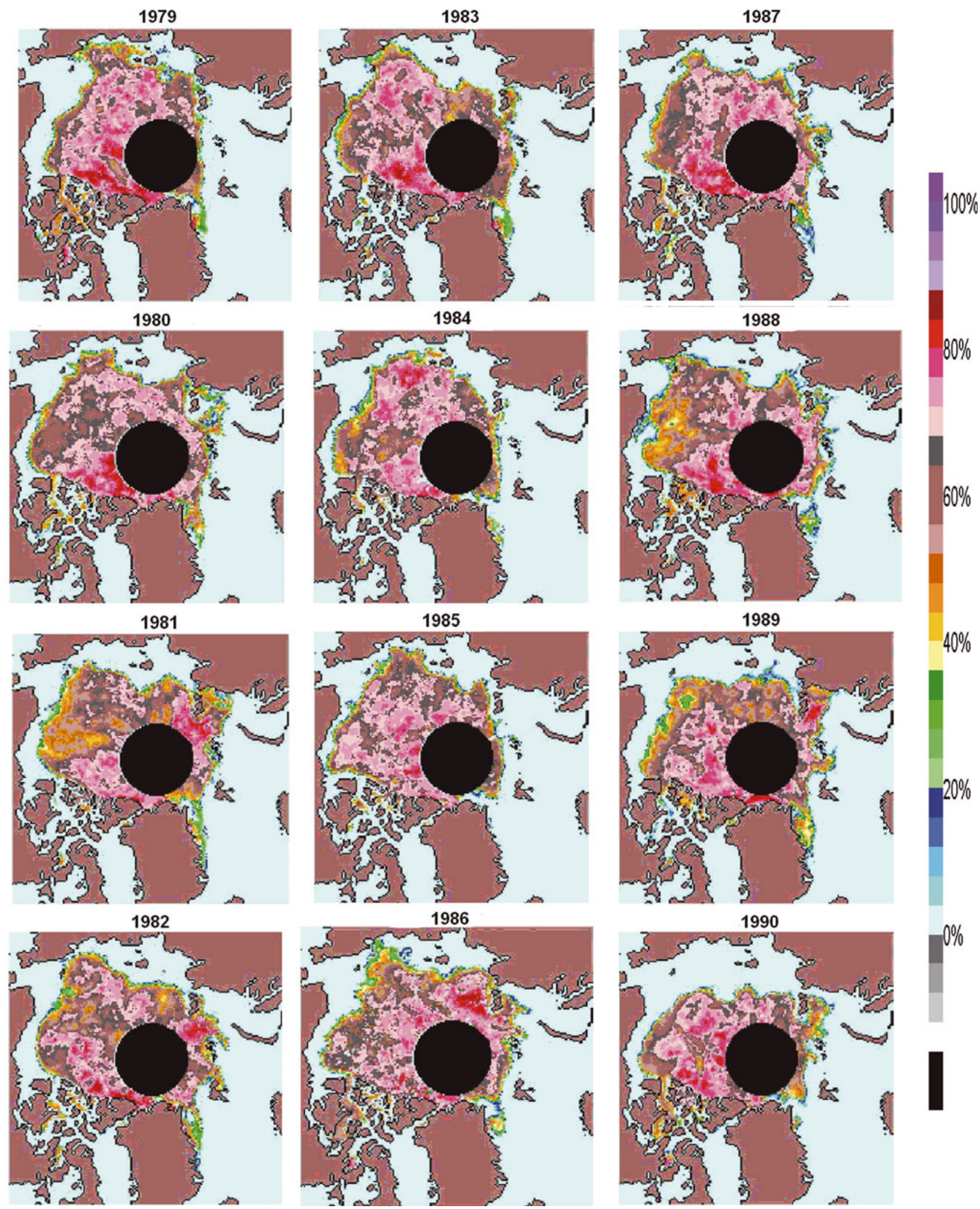

Fig. 6. Minimum sea-ice concentrations, $C_{\mathrm{LTM}}$, at the LTMs from 1979 to 2002 over the ice pack surviving the summer melting. $C_{\mathrm{LTM}}$ are less than the values of $C_{S M}$ at the single-day $\mathrm{SM}$, which include some new ice as well as some ice that has not yet melted.

the higher latitudes (e.g. 19 July, day 200), marking an earlier transition from melting to freezing at the colder latitudes. Although the later TOOs (e.g. days 260-272) tend to be near the edge of the perennial ice pack, considerable variability of LTM occurs over the pack in each year, and from year to year, reflecting the large variability in the meteorological forcing. This is also shown in the histograms of TOO in Figure 8 and the average TOOs over the perennial ice pack. For example, the summers of 1983 and 2000 had a relatively large number of early TOO (days 180 to 205) at high latitudes (Figs 7 and 8). In contrast, the summers of 1989 and 2002 had a higher frequency of late 

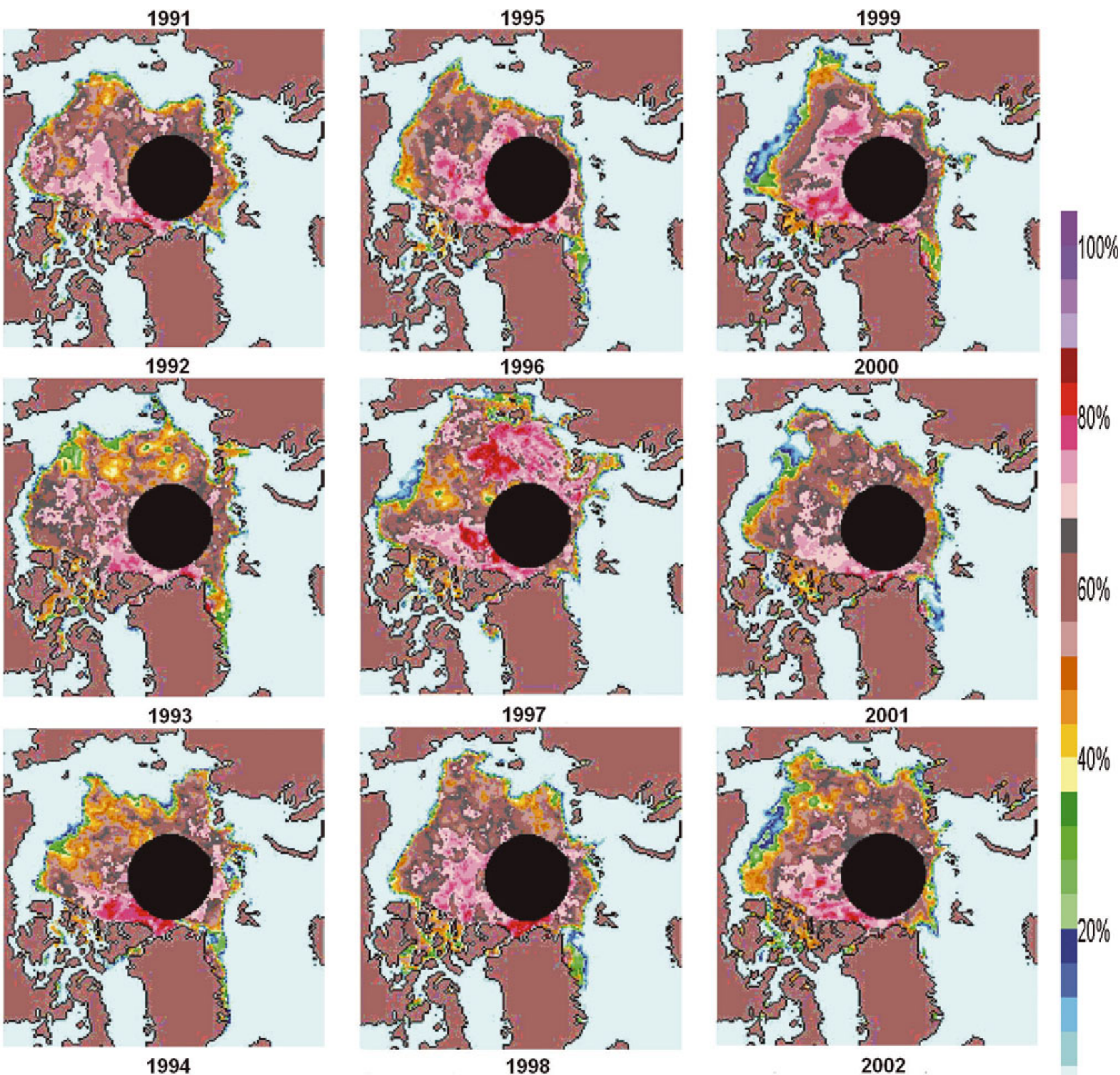

1997
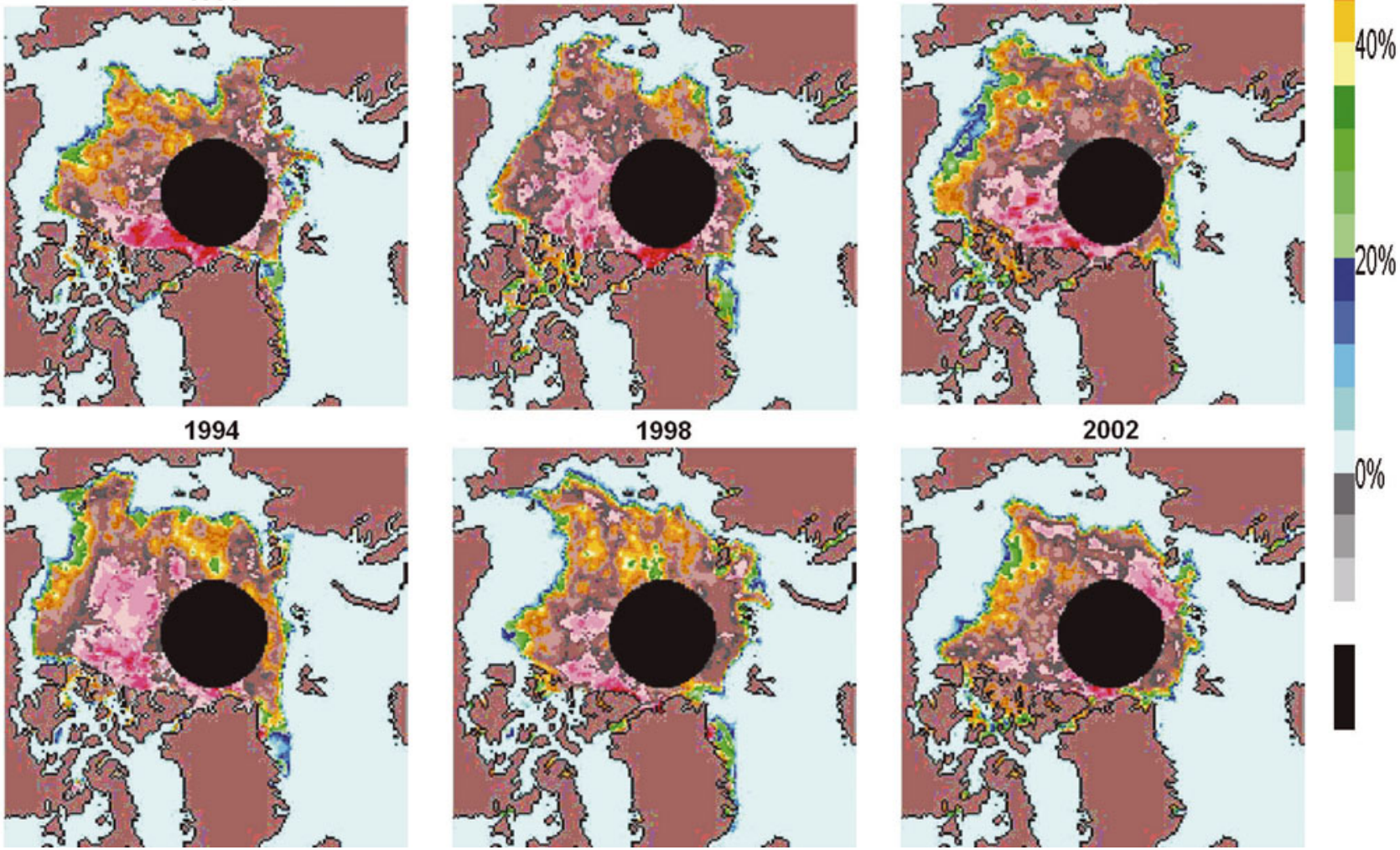

Fig. 6. (continued)

TOO (around day 260) and the latest average TOO of 28 August (day 240).

Contiguous map elements with the same color have TOO of LTM values within 6 days. These areas with similar TOO are typically several hundred kilometers across, which is about ten times the size of the map elements for which the
$C_{\mathrm{LTM}}$ are calculated, indicating spatial coherence of the TOO patterns. In some cases, adjoining areas have TOO values that are similar and others are abruptly different. Although one might expect the pattern of TOO to be more smoothly varying over the ice pack, we believe the observed spatial coherence of the TOO, on the scale of several hundred 

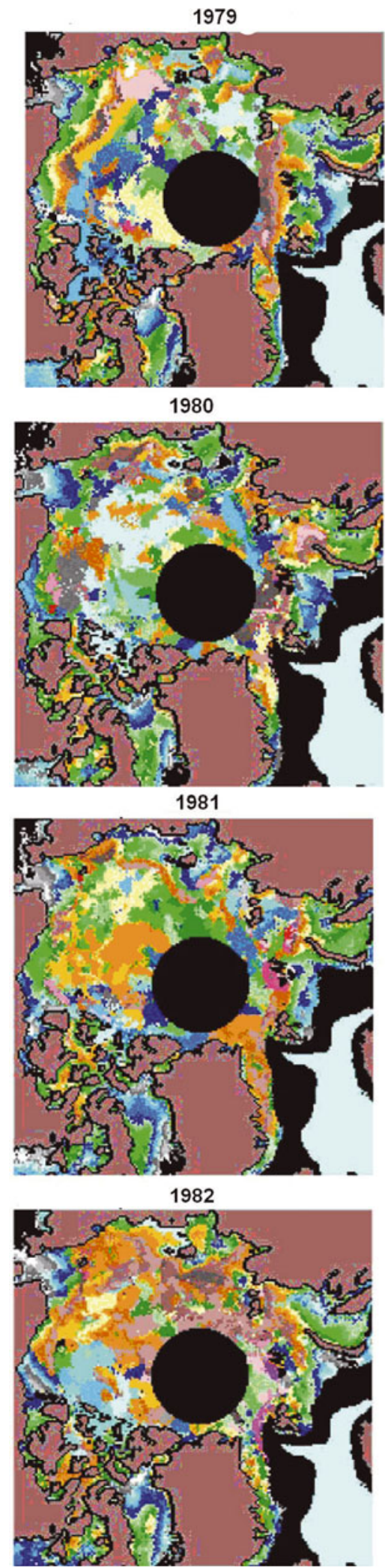

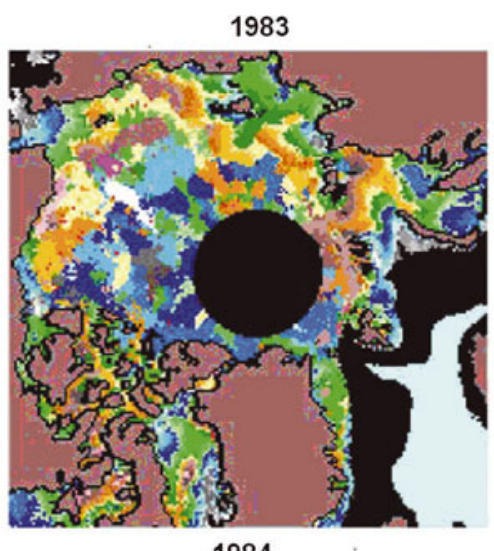

1984

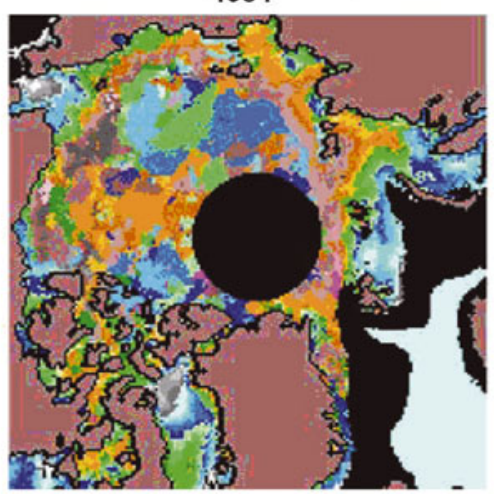

1985

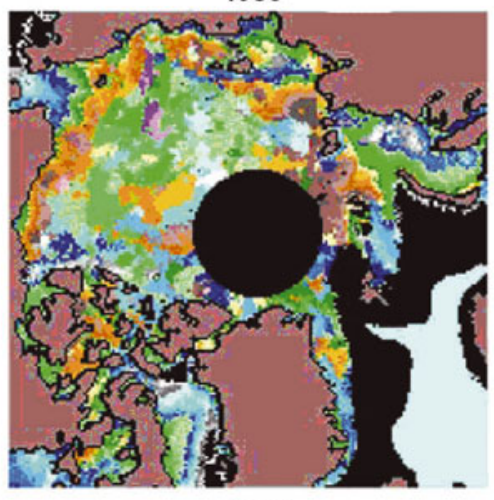

1986

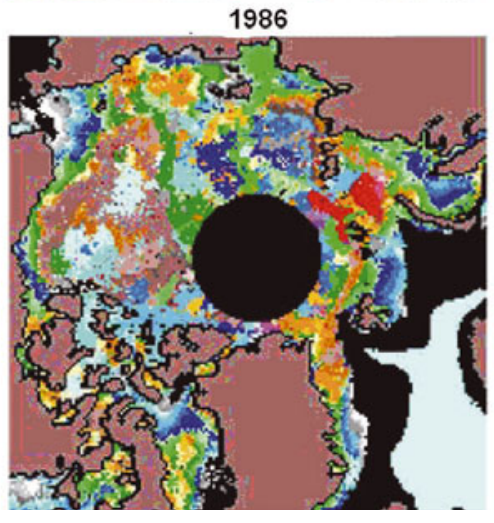

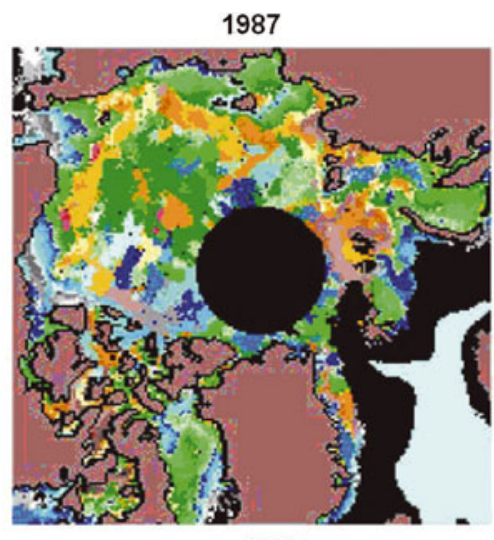

1988

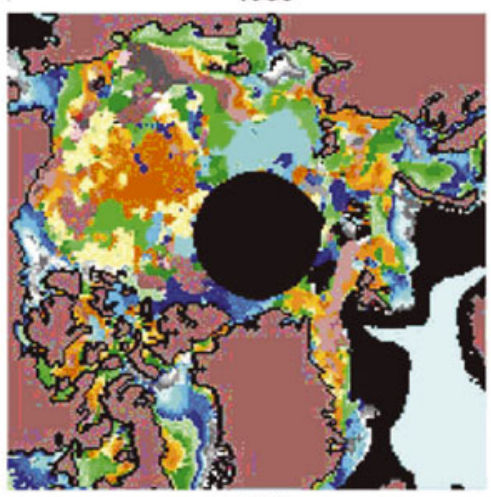

1989

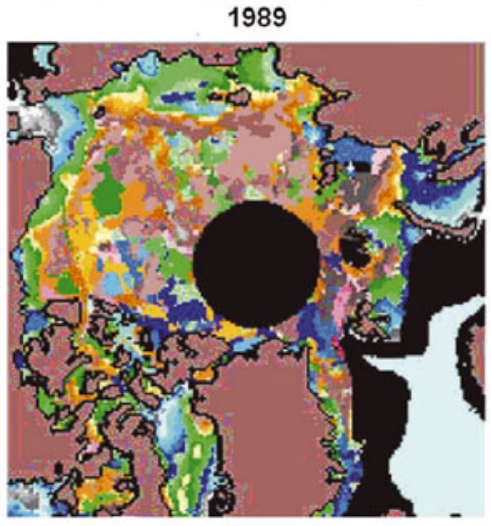

1990

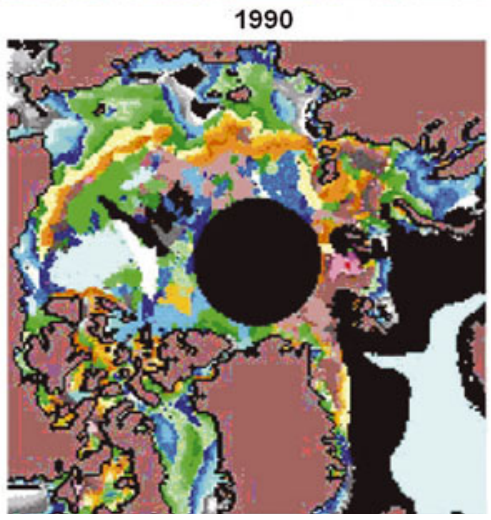

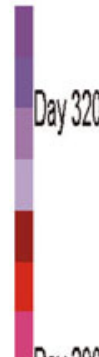

Day 290

Day 260

Day 200

Day 170

Day 230

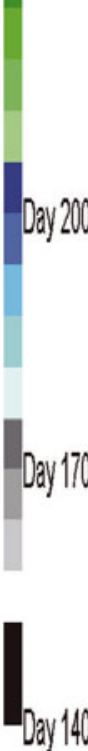

Day 140

Fig. 7. Maps of the times of occurrence (TOO) of the LTMs from 1979 to 2002 . TOO are shown for both the region outside the area of the surviving summer pack, where $C_{\mathrm{LTM}}=0$, and within the surviving pack, where $C_{\mathrm{LTM}}>0$. In the regions of the seasonal ice zone most distant from the surviving pack where the sea ice retreats first, the TOO are earliest (e.g. day $<200$ ), as expected. Closer to the outer edge of the surviving pack, the TOO are mostly in September around the time of the SM.

kilometers, with some abrupt changes in adjacent areas, reflects the interaction of the ice pack with the spatial scale of weather patterns that influence the sea-ice concentration and the melt-freeze transition at the end of the summer.
Some of the examples of abrupt differences in adjacent areas are in the seasonal ice zone where ice retreats first early in the season generally from the south and then late in the season near the edge of the summer pack. 

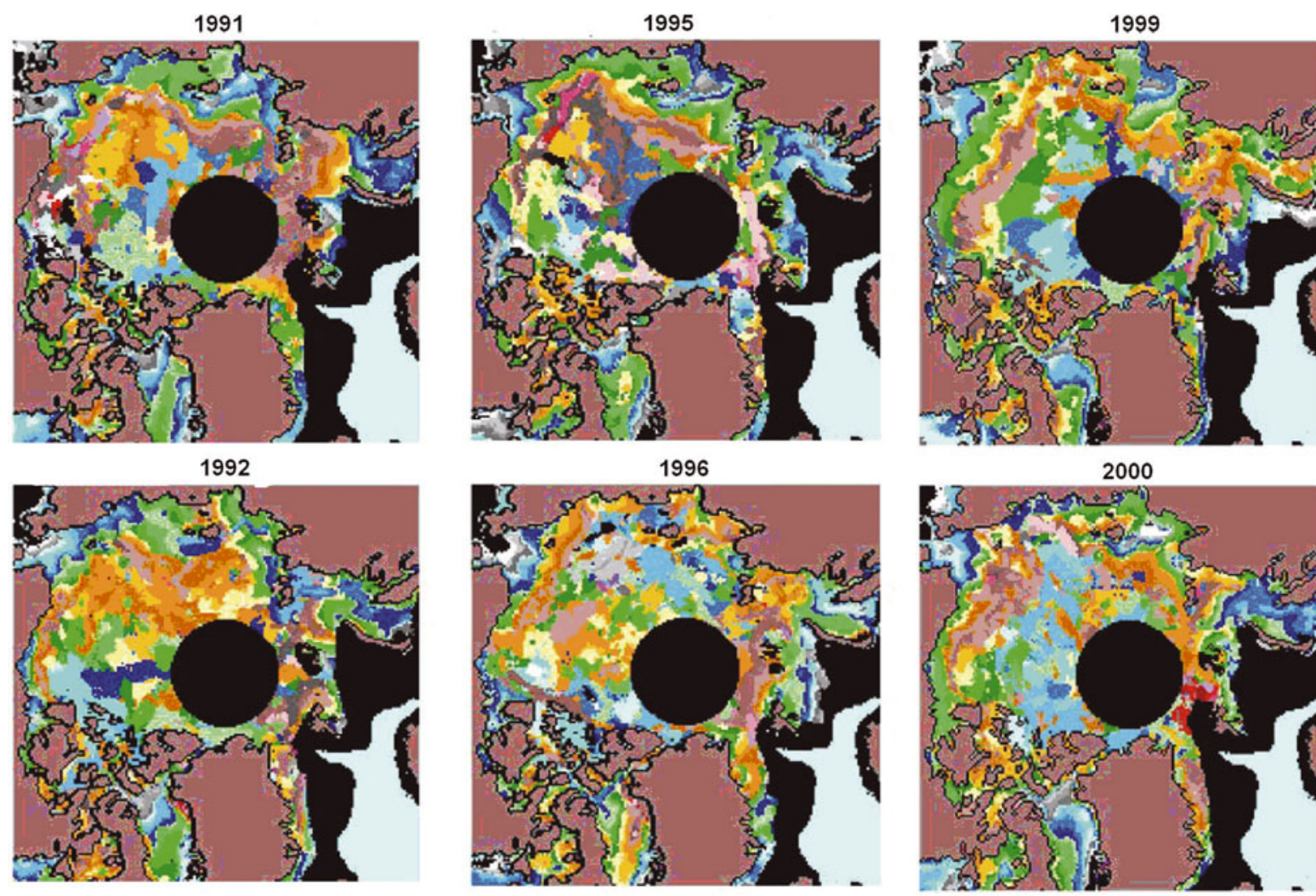

Day 290
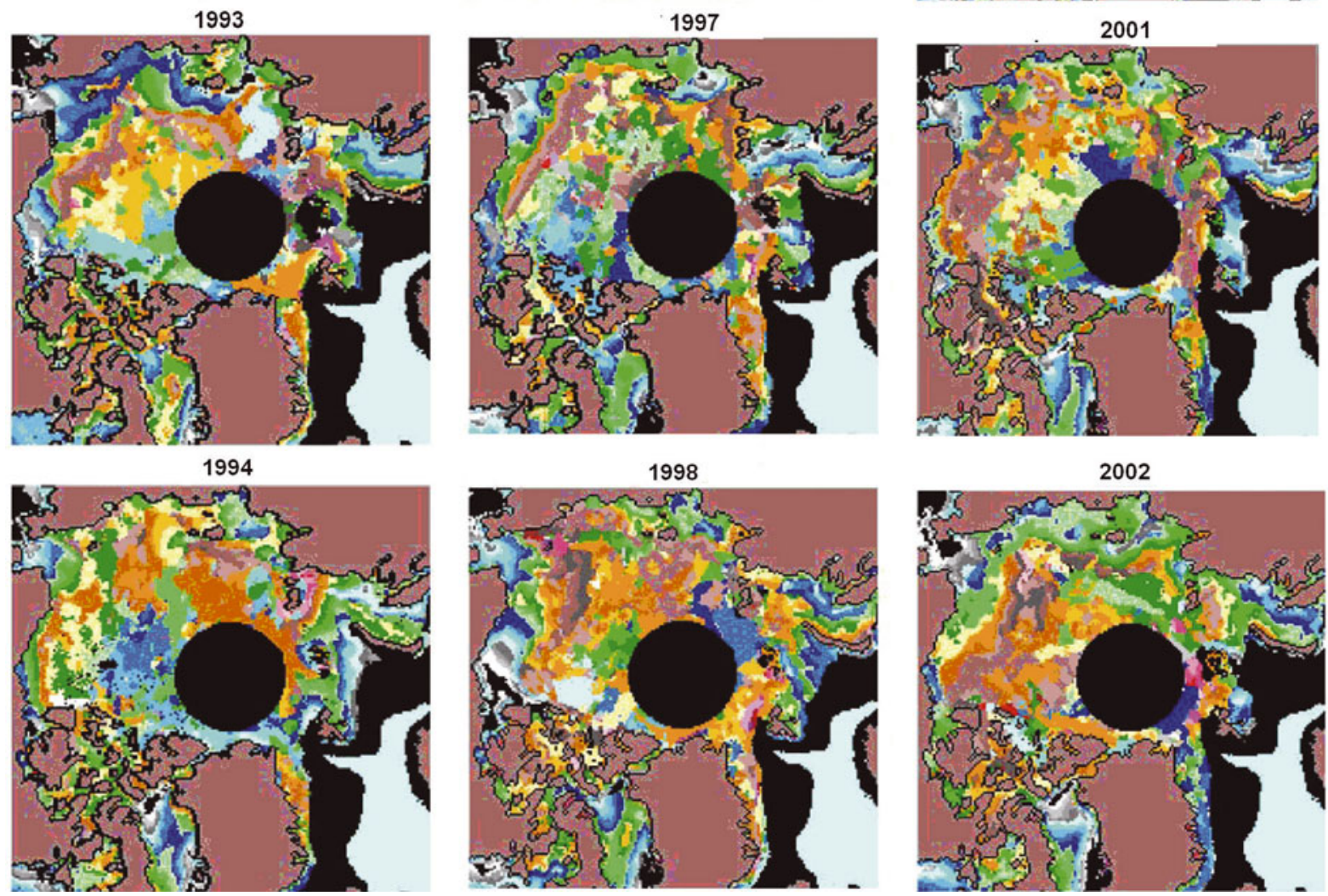

Day 170
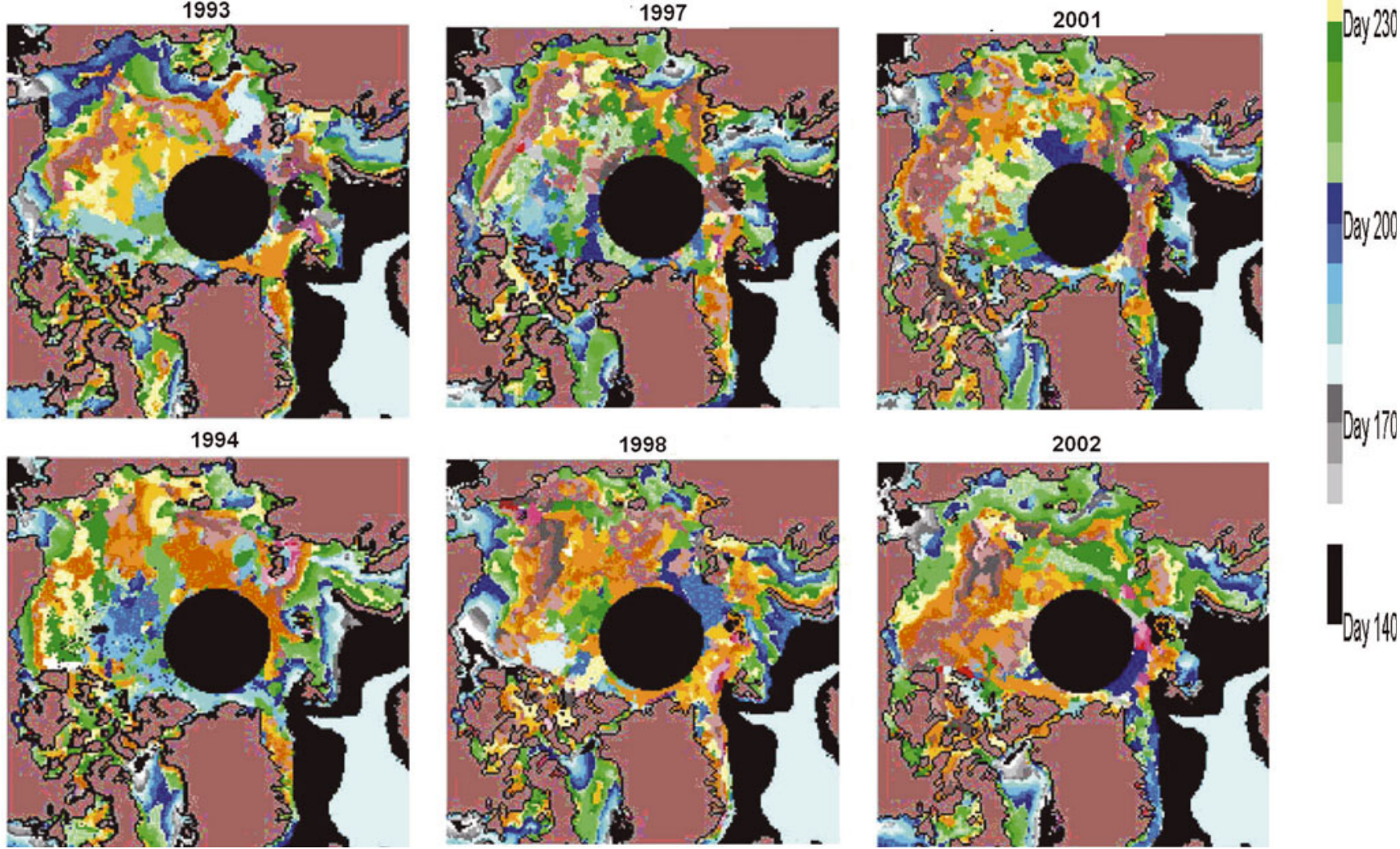

Fig. 7. (continued)

For the few adjacent areas within the pack with abrupt differences, it is likely that the $C_{\mathrm{T}}$ have more than one near-minimum, separated in time. It is analogous to a region of several hundred kilometers having a maximum summer temperature in early July, while an adjacent region might have a maximum in late August, with border areas having near-minima in both early July and late August.
Also, these areas of spatial coherence are large compared to typical distances of ice advection during the time the $C_{\mathrm{LTM}}$ is determined, since rates of ice advection are typically a few kilometers per day (e.g. Thorndike and Colony, 1982, and drift rates of locations in Fig. 5). This is important for our assumption that the effects of advection are not large. 

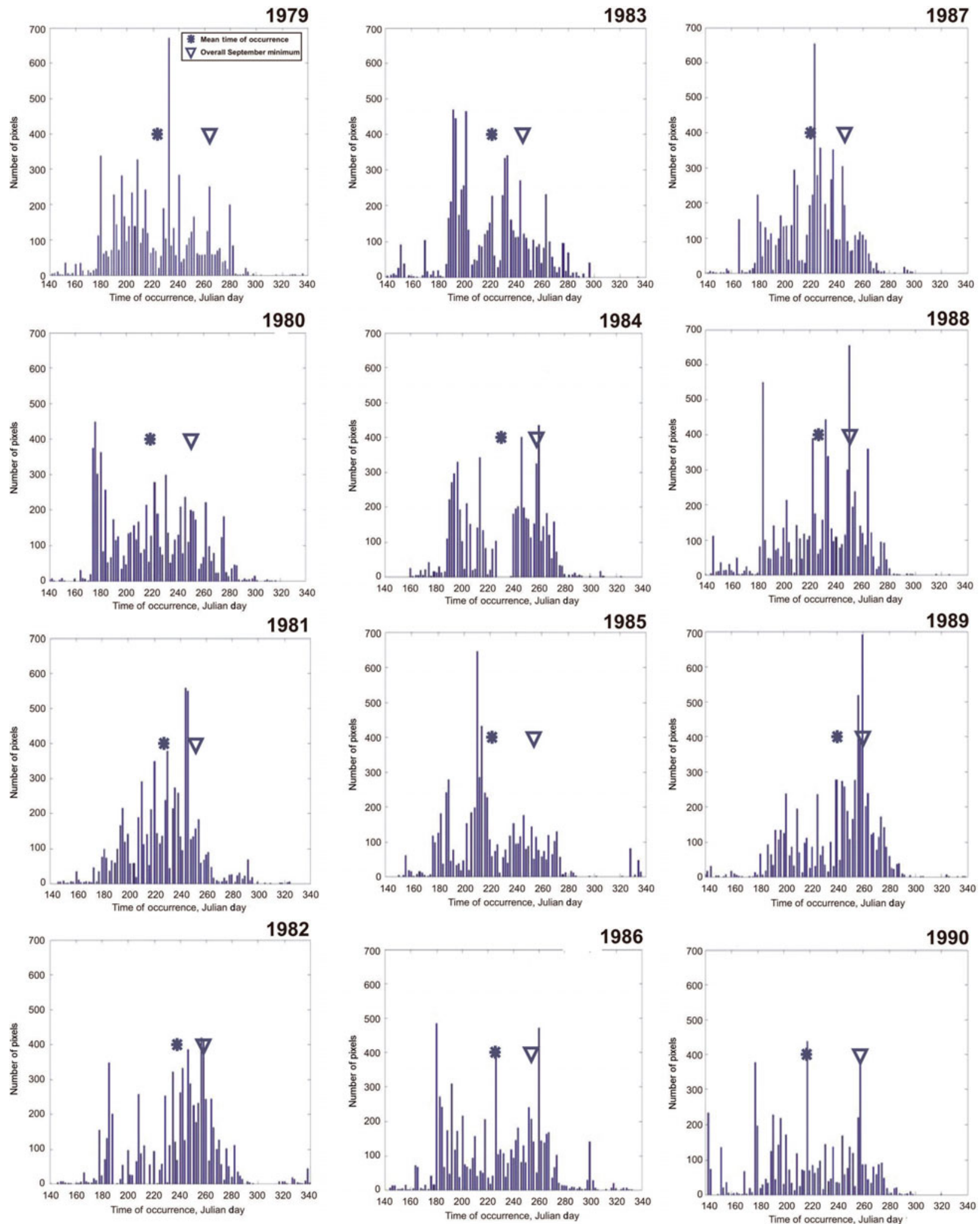

Fig. 8. Histograms of the times of occurrence (TOO) of the LTMs from 1979 to 2002 and the average TOO for the region within the ice pack surviving the summer melt (i.e. where $C_{\mathrm{LTM}} \geq 10 \%$ ). The average TOO generally precedes the time of the overall summer minimum, because the melt-freeze transition tends to occur earlier at locations within the pack than it does at the edges of the pack.

\section{DISCUSSION OF 24 YEAR RECORD OF AVERAGE TOO, TOTAL AGGREGATE LTM SEA-ICE AREA AND SM SEA-ICE AREA}

Over the 24 year span, the average TOO (Fig. 9) varied by 32 days from 6 August (day 218) in 1990 to 28 August (day 240) in 1989 and 2002, whereas the time of the overall minimum (Fig. 1) varied slightly less, by 26 days, from 5 September (day 248) in 1987 to 1 October (day 274) in 1995. The average TOO always preceded the time of the overall minimum (Fig. 8).

The 24 year record of $C_{\mathrm{LTM}}$ varies markedly from year to 

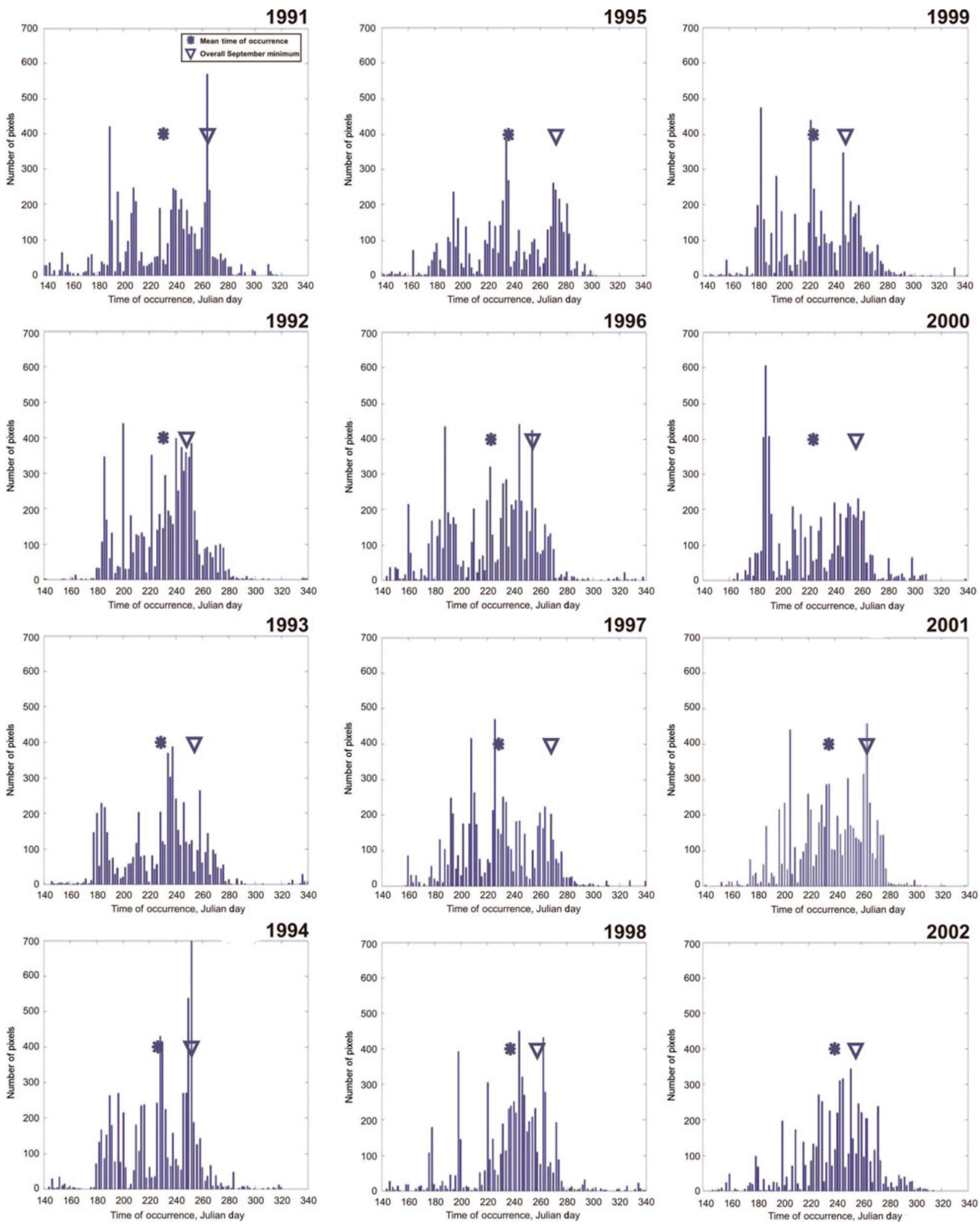

Fig. 8. (continued)

year, both in spatial distribution (Fig. 6) and in the aggregate ice area surviving the summer melt, $A_{\mathrm{LTM}}$ (Fig. 9). Areas with the largest $C_{\mathrm{LTM}}, \sim 80 \%$, tend to be at higher latitudes, but some are close to the edge of the surviving pack. The two most extreme minima occurred in the summers of 1993 and 2002, when the ice cover was minimal across the eastern Arctic from the Beaufort Sea through to the Laptev Sea. Figure 9 also shows the relationship between the average
TOO and the $A_{\mathrm{LTM}}$ over the 24 years. Typical interannual variations in $A_{\mathrm{LTM}}$ are $\sim 10-15 \%$. The earliest average TOO and one of the latest average TOO are in successive years (1989 and 1990). On a year-to-year basis, a consistent relation between later average TOO and smaller $A_{\mathrm{LTM}}$ does not appear because of the large interannual variability.

However, the $A_{\text {LTM }}$ and the average TOO have opposite linear trends, showing that the area of surviving ice decreases 


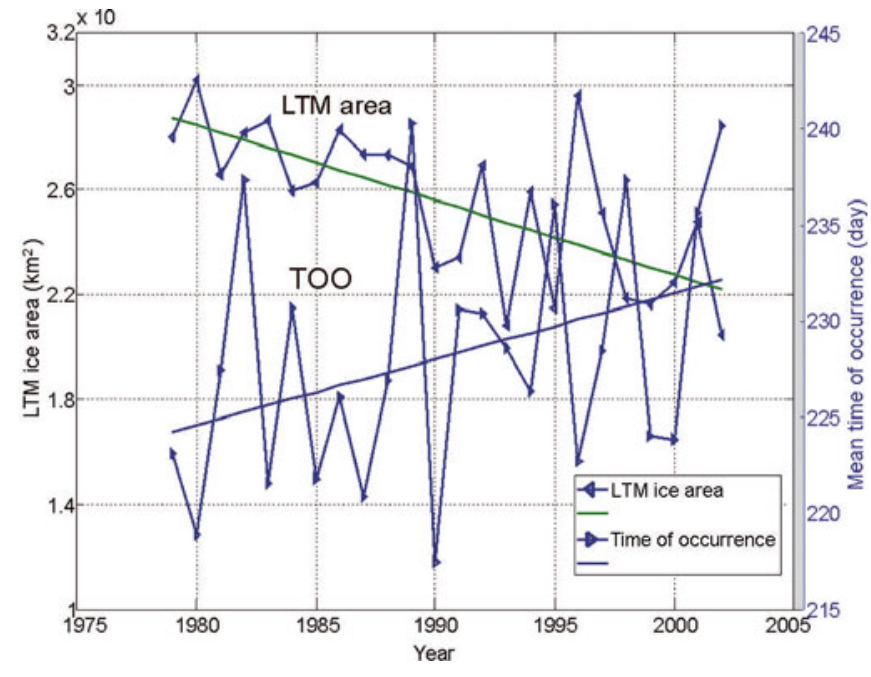

Fig. 9. Comparison of LTM sea-ice areas and average times of occurrence of the LTM from 1979 to 2002 showing opposite trends with time.

as the TOO becomes later in the season. The $A_{\mathrm{LTM}}$ declined by $0.27 \times 10^{6} \mathrm{~km}^{2}(10 \mathrm{a})^{-1}\left(9.5 \pm 2.2 \%(10 \mathrm{a})^{-1}\right)$ which is similar to the $8.9 \pm 2.0 \%(10 \mathrm{a})^{-1}$ in the overall summer minimum (Fig. 10) and previous values $\left(7.7 \pm 3 \%(10 \mathrm{a})^{-1}\right.$ : Stroeve and others, 2005; $9.8 \pm 1.5 \%(10 a)^{-1}$ : Comiso, 2006). The average TOO over the perennial ice pack increased by 8 days from around 11 to 19 August, indicating a later ending of the melt season by $\sim 3$ days $(10 a)^{-1}$, on average, as the $A_{\mathrm{LTM}}$ declined.

Figure 10 shows the $A_{\mathrm{LTM}}$ from Figure 9, along with a similar calculation for those areas for which $C_{\mathrm{LTM}} \geq 20 \%$. The two $A_{\mathrm{LTM}}$ differ by $<2 \%$, indicating a sharp boundary in the LTM ice pack at the end of summer. Also shown are the areas at the overall summer minimum $\left(A_{\mathrm{SM}}\right)$ and the total multi-year ice areas $\left(A_{\mathrm{pMY}}\right)$ for the following February of each year calculated for all $C_{\mathrm{pMY}}$ and for $C_{\mathrm{pMY}} \geq 20 \%$. The $20 \%$ limit is used to depict the extremity of the Arctic multiyear ice pack (e.g. Gloersen and others, 1992), because it gives a sharper edge in the map. The two estimates of multiyear areas in winter differ by $0.45 \times 10^{6} \mathrm{~km}^{2}$, on average. In contrast, the small difference in the corresponding two $A_{\mathrm{LTM}}$ is consistent with a spreading of the multi-year ice near the edge of the multi-year ice pack between the end of the melt season and midwinter, as can be seen by the comparison of gradients of $C, C_{\mathrm{PMY}}$ and $C_{\mathrm{LTM}}$ and in Figures 1,2 and 6 . The residual difference between $A_{\mathrm{LTM}}$ and $A_{\mathrm{PMY}}$ is $0.45 \times$ $10^{6} \mathrm{~km}^{2}$, indicating that the $A_{\mathrm{pMY}}$ from passive microwave measures $\sim 83 \%$ of the multi-year ice area, which is a substantially smaller difference than previously suggested by comparison with $A_{\mathrm{SM}}$ (e.g. Comiso, 1990). Other algorithms for the passive microwave might improve the measurement of the multi-year ice; for instance, Johannessen and others (1999) suggested a smaller difference between the overall September minimum and the $A_{\mathrm{pMY}}$ the following winter from the NORSEX sea-ice algorithm.

Over 24 years, the average $A_{\text {LTM }}$ is $2.6 \times 10^{6} \mathrm{~km}^{2}$ (excluding $\sim 0.7 \times 10^{5} \mathrm{~km}^{2}$ above $84^{\circ} \mathrm{N}$ ), which is substantially less than the average $A_{\mathrm{SM}}$ of $3.8 \times 10^{6} \mathrm{~km}^{2}$. Although $A_{\mathrm{SM}}$ has often been used as the best estimate of the area of ice that survives the summer, it is $\sim 45 \%$ too large. However, the slopes of the trend lines over 24 years are very similar for the three parameters $A_{\mathrm{LTM}}, A_{\mathrm{SM}}$ and $A_{\mathrm{pM}}$. On a year-toyear basis, the $A_{\mathrm{LTM}}$ and $A_{\mathrm{SM}}$ are highly correlated $(R=0.99)$, but neither are as well correlated with $A_{\mathrm{pMY}}$ ( $R=0.92$ for both).

\section{CONCLUSIONS}

The $A_{\text {LTM }}$ aggregate sea-ice area calculated at the LTM provides an improved estimate of the area of ice surviving the summer melt season to become multi-year ice (i.e. $A_{M Y}$ ). The LTM method attempts to capture the local minima ice areas in $25 \mathrm{~km}$ cells at the local melt-freeze transitions that occur at different times in different locations over the Arctic Ocean. In contrast, the widely used $A_{\mathrm{SM}}$ observed at the SM overestimates the surviving ice by $\sim 45 \%$, because it does not account for the non-simultaneity of the melt-freeze transition at all locations. At locations mostly near the outer edge of the pack, the $A_{\mathrm{SM}}$ includes some ice that does not survive the summer melting. At locations farther within the pack, the $A_{\mathrm{SM}}$ typically includes some new ice that formed after the local melt-freeze transition.

There are essentially two types of errors in estimating the area of multi-year ice at the end of the melt season: (1) errors in the passive-microwave determination of sea-ice concentration, which tend to be common to both the LTM and the SM method, and (2) errors in the method of selection of the ice that survives the summer melt. We describe our assumptions of the LTM method and attempt to estimate errors including the effects of thermodynamics and ice dynamics on the selected minimum ice concentration, which we believe are significantly lower for the LTM method. Spatial variation of the timing of the selection of the minima relative to new ice formation and the end of melting of old ice are critical factors in the LTM method. In future research, residual effects of ice advection on the selection of $C_{\mathrm{LTM}}$ can be reduced by using ice velocity fields for Lagrangian tracking of the $C_{\mathrm{T}}(t)$.

The $A_{\text {LTM }}$ declined by $0.27 \times 10^{6} \mathrm{~km}^{2}(10 \mathrm{a})^{-1} \quad(9.5 \pm$ $\left.2.2 \%(10 \mathrm{a})^{-1}\right)$ which is similar to the declines in both $A_{\mathrm{SM}}$ and $A_{\mathrm{pMY}}$, even though the magnitudes of these three parameters differ significantly. Also, the interannual variations in $A_{\mathrm{LTM}}$ and $A_{\mathrm{SM}}$ are highly correlated as well as having the same long-term trends, showing that both parameters are valid indicators of climatic variation in the late-summer ice pack. Over the 24 years, the average TOO over the perennial ice pack increased by 8 days from around 11 to 19 August, indicating a later ending of the melt season by 3 days $(10 \mathrm{a})^{-1}$ as the $A_{\mathrm{LTM}}$ declined. This is consistent, for example, with a shortening of the ice season in the seasonal sea-ice zone of the Arctic Ocean by 5 days $(10 \mathrm{a})^{-1}$ from 1979 to 1996 (Parkinson, 2000). In the last 5-10 years, the rate of summer sea-ice decline of the summer sea-ice area appears to have been accelerating, and various authors have predicted the disappearance of most of the summer pack in a few decades, as discussed, for example, by Meier and others (2007).

The residual difference between the $A_{\mathrm{LTM}}$ and the $A_{\mathrm{pMY}}$ passive-microwave estimates of winter multi-year ice is $\sim 0.45 \times 10^{6} \mathrm{~km}^{2}$, indicating the passive-microwave algorithm we used is detecting $\sim 83 \%$ of the multi-year ice in winter. Although the multi-year trends in $A_{\mathrm{PMY}}$ and $A_{\mathrm{LTM}}$ are essentially the same, their interannual variations are not as well correlated as $A_{\mathrm{LTM}}$ and $A_{\mathrm{SM}}$, suggesting that the passivemicrowave signature used for $C_{\mathrm{pMr}}$ might also have some 


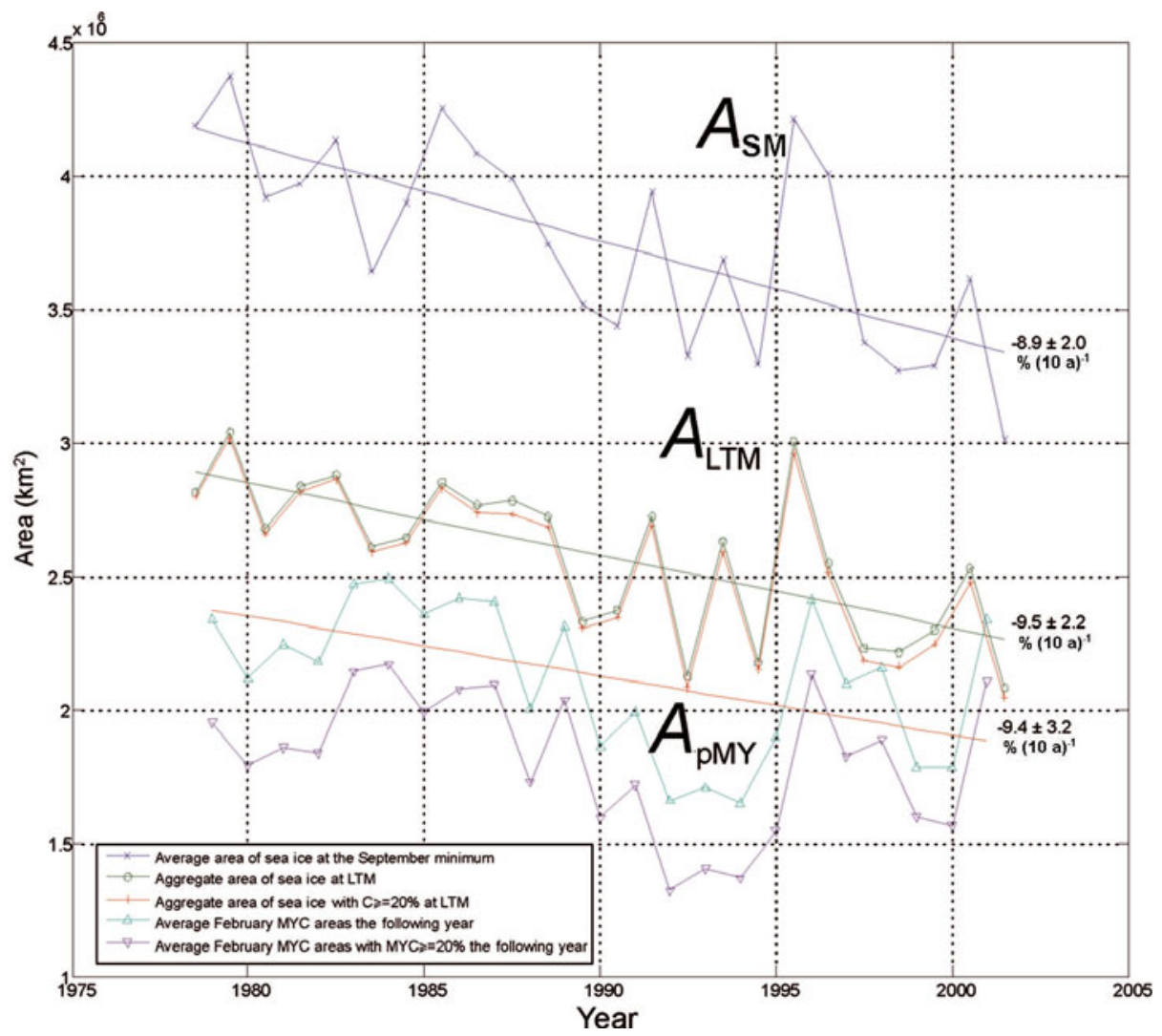

Fig. 10. Comparison of the $S M$ ice area $\left(A_{S M}\right)$, the aggregate area of ice at the local temporal minima $\left(A_{\mathrm{LTM}}\right)$ and a passive-microwave estimate of the February multi-year sea-ice area $\left(A_{\mathrm{pMY}}\right)$ from 1979 to 2002 showing similar linear trends in the three parameters.

interannual variability. Our values of $A_{\text {LTM }}$ should provide a new improved baseline for evaluating various methods of determining the area of multi-year ice within the pack, using either passive- or active-microwave techniques.

\section{REFERENCES}

Andersen, S., R. Tonboe, S. Kern and H. Schyberg. 2006. Improved retrieval of sea ice total concentration from spaceborne passive microwave observations using numerical weather prediction model fields: an intercomparison of nine algorithms. Remote Sens. Environ., 104(4), 374-392.

Carsey, F.D. 1985. Summer Arctic sea ice character from satellite microwave data. J. Geophys. Res., 90(C3), 5015-5034.

Cavalieri, D.J., P. Gloersen and W.J. Campbell. 1984. Determination of sea ice parameters with the NIMBUS 7 SMMR. J. Geophys. Res., 89(D4), 5355-5369.

Cavalieri, D.J. and 6 others. 1991. Aircraft active and passive microwave validation of sea ice concentration from the Defense Meteorological Satellite program special sensor microwave imager. J. Geophys. Res., 96(C12), 21,989-22,008.

Cavalieri, D.J., K.M.S. Germain and C.T. Swift. 1995. Reduction of weather effects in the calculation of sea-ice concentration with the DMSP SSM/I. J. Glaciol., 41(139), 455-464.

Cavalieri, D.J., C.L. Parkinson and K.Y. Vinnikov. 2003. 30-year satellite record reveals contrasting Arctic and Antarctic decadal sea ice variability. Geophys. Res. Lett., 30(18), 1970. (10.1029/ 2003GL018031.)

Comiso, J.C. 1990. Arctic multiyear ice classification and summer ice cover using passive microwave satellite data. J. Geophys. Res., 95(C8), 13,411-13,422.

Comiso, J.C. 2006. Arctic warming signals from satellite observations. Weather, 61(3), 70-76.
Fetterer, F. and N. Untersteiner. 1998. Observations of melt ponds on Arctic sea ice. J. Geophys. Res., 103(C11), 24,821-24,835.

Gloersen, P. and D.J. Cavalieri. 1986. Reduction of weather effects in the calculation of sea ice concentration from microwave radiances. J. Geophys. Res., 91(C3), 3913-3919.

Gloersen, P., W.J. Campbell, D.J. Cavalieri, J.C. Comiso, C.L. Parkinson and H.J. Zwally. 1992. Arctic and Antarctic sea ice, 19781987: satellite passive-microwave observations and analysis. Washington, DC, National Aeronautics and Space Administration. (NASA SP-511.)

Gogineni, S.P., R.K. Moore, T.C. Grenfell, D.G. Barber, S.A. Digby and M. Drinkwater. 1992. The effects of freeze-up and melt processes on microwave signatures. In Carsey, F.D. and 7 others, eds. Microwave remote sensing of sea ice. Washington, DC, American Geophysical Union, 329-341.

Hibler, W.D., III. 1974. Differential sea-ice drift. II. Comparison of mesoscale strain measurements to linear drift theory predictions. J. Glaciol., 13(69), 457-471.

Johannessen, O.M., E.V. Shalina and M.W. Miles. 1999. Satellite evidence for an Arctic sea ice cover in transformation. Science, 286(5446), 1937-1939.

Kwok, R., H.J. Zwally and D. Yi. 2004. ICESat observations of Arctic sea ice: a first look. Geophys. Res. Lett., 31(16), L16401. (10.1029/2004GL020309.)

Laxon, S., N. Peacock and D. Smith. 2003. High interannual variability in sea ice thickness in the Arctic region. Nature, 425(6961), 947-950.

Meier, W.N., J. Stroeve and F. Fetterer. 2007. Whither Arctic sea ice? A clear signal of decline regionally, seasonally and extending beyond the satellite record. Ann. Glaciol., 46, 428-434.

Parkinson, C.L. 2000. Variability of Arctic sea ice: the view from space, an 18-year record. Arctic, 53(4), 341-358.

Parkinson, C.L., D.J. Cavalieri, P. Gloersen, H.J. Zwally and J.C. Comiso. 1999. Arctic sea ice extents, areas, and trends, 1978-1996. J. Geophys. Res., 104(C9), 20,837-20,856. 
Perovich, D.K., W.B. Tucker, III and K.A. Ligett. 2002. Aerial observations of the evolution of ice surface conditions during summer. J. Geophys. Res., 107(C10), 8048. (10.1029/2000JC000449.)

Stroeve, J.C. and 6 others. 2005. Tracking the Arctic's shrinking ice cover: another extreme September minimum in 2004. Geophys. Res. Lett., 32(4), (L04501). (10.1029/2004GL021810.)

Thorndike, A.S. and R. Colony. 1982. Sea ice motion in response to geostrophic winds. J. Geophys. Res., 87(C8), 5845-5852.

Thorndike, A.S., D.A. Rothrock, G.A. Maykut and R. Colony. 1975. The thickness distribution of sea ice. J. Geophys. Res., 80(33), $4501-4513$.
Zwally, H.J. and J.E. Walsh. 1987. Comparison of observed and modeled ice motion in the Arctic Ocean. Ann. Glaciol., 9, 136-144.

Zwally, H.J., J.C. Comiso, C.L. Parkinson, D.J. Cavalieri and P. Gloersen. 2002. Variability of Antarctic sea ice 1979-1998. J. Geophys. Res., 107(C5), 3041. (10.1029/2000JC000733.)

Zwally, H.J., R. Yi, R. Kwok and Y. Zhao. 2008. ICESat measurements of sea-ice freeboard and estimates of sea-ice thickness in the Weddell Sea. J. Geophys. Res., 113(C2), C02515. (10.1029/ 2007JC004284.)

MS received 30 June 2006 and accepted in revised form 25 November 2007 